Bollapragada, Srinivas, and Suman Mallik. "Managing On-air Ad Inventory in Broadcast Television." IIE Transactions 40.12

(2008): 1107-123. Publisher's official version: http://dx.doi.org/10.1080/07408170802323026. Open Access version:

http://kuscholarworks.ku.edu/dspace/.

Please share your stories about how Open Access to this item benefits you.

[This document contains the author's accepted manuscript. For the publisher's version, see the link in the header of this document.]

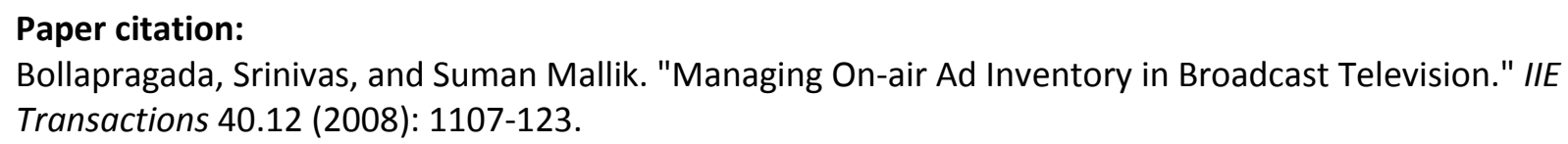

\title{
Keywords:
}

Broadcast Television, Uncertainty, Services Management

\begin{abstract}
:
Motivated by the experiences of the National Broadcasting Company (NBC), we present an analytical model for managing on-air ad inventory in broadcast television. The ad inventory in this industry is priced based on rating points or the number of viewers that watch a commercial. The rating points during a broadcast year are sold through two distinct processes: the Upfront, which occurs before the broadcast season, and the Scatter, which occurs during the broadcast season. A firm needs to allocate its total rating points inventory to these two markets before knowing either the performance rating of its shows or the Scatter market price, both of which are random. The networks offer ratings (performance) guarantees on the inventory that is sold in the Upfront market while such guarantees are seldom offered in the Scatter market. We propose an optimization model for the networks to manage their rating points inventory. Our model explicitly incorporates the performance uncertainty of the television shows as well as the revenue uncertainty of the Scatter market. We derive conditions for feasibility of the problem and characterize the optimal amount of rating points to sell in the Upfront market. Our model explains the current practice of selling around $60-80 \%$ of the total rating points for the season during the Upfront market and analyzes other common strategies used by the firms. In addition to providing key managerial insights, our work introduces quantitative methodologies to television networks in planning their Upfront markets.
\end{abstract}

Text of paper:

\section{Managing On-Air Ad Inventory in Broadcast Television}

\author{
Srinivas Bollaparagda \\ bollapragada@research.ge.com \\ GE Global Research Center \\ 1 Research Circle \\ Schenectady, NY 12309
}

\author{
Suman Mallik \\ suman@ku.edu \\ School of Business \\ University of Kansas \\ 1300 Sunnyside Avenue \\ Lawrence, KS 66045
}

\author{
May 2007 \\ Revised November 2007 \\ Forthcoming in IIE Transactions
}


Bollapragada, Srinivas, and Suman Mallik. "Managing On-air Ad Inventory in Broadcast Television." IIE Transactions 40.12 (2008): 1107-123. Publisher's official version: http://dx.doi.org/10.1080/07408170802323026. Open Access version: http://kuscholarworks.ku.edu/dspace/.

Please share your stories about how Open Access to this item benefits you.

\begin{abstract}
Motivated by the experiences of the National Broadcasting Company (NBC), we present an analytical model for managing on-air ad inventory in broadcast television. The ad inventory in this industry is priced based on rating points or the number of viewers that watch a commercial. The rating points during a broadcast year are sold through two distinct processes: the Upfront, which occurs before the broadcast season, and the Scatter, which occurs during the broadcast season. A firm needs to allocate its total rating points inventory to these two markets before knowing either the performance rating of its shows or the Scatter market price, both of which are random. The networks offer ratings (performance) guarantees on the inventory that is sold in the Upfront market while such guarantees are seldom offered in the Scatter market. We propose an optimization model for the networks to manage their rating points inventory. Our model explicitly incorporates the performance uncertainty of the television shows as well as the revenue uncertainty of the Scatter market. We derive conditions for feasibility of the problem and characterize the optimal amount of rating points to sell in the Upfront market. Our model explains the current practice of selling around 60$80 \%$ of the total rating points for the season during the Upfront market and analyzes other common strategies used by the firms. In addition to providing key managerial insights, our work introduces quantitative methodologies to television networks in planning their Upfront markets.
\end{abstract}

\title{
Key Words: Broadcast Television, Uncertainty, Services Management
}


Bollapragada, Srinivas, and Suman Mallik. "Managing On-air Ad Inventory in Broadcast Television." IIE Transactions 40.12

(2008): 1107-123. Publisher's official version: http://dx.doi.org/10.1080/07408170802323026. Open Access version:

http://kuscholarworks.ku.edu/dspace/.

Please share your stories about how Open Access to this item benefits you.

\section{INTRODUCTION}

This work, motivated by the experiences of National Broadcasting Company (NBC), presents an analytical model for managing on-air ad inventory in broadcast television. The practice in the broadcast television industry is to sell the ad inventory through two distinct processes: the Upfront selling and the Scatter selling. A broadcast year in network television in the United States of America begins in the third week of September. Upfront market typically occurs at the end of the month of May, much before the start of the actual broadcast season. At this time, the broadcast networks unveil their fall prime-time program schedule and tempt the big advertisers and media buyers to buy airtime in bulk for the entire year. The remaining inventory after the Upfront market is available for sale in the Scatter market, which occurs throughout the broadcast season.

The performance of television shows is measured using Nielsen rating points, which are measures of the number of people that watch the shows. A rating point is equal to one percent of all US households with television sets. The gross rating points (GRP) of a network during a broadcast year is the sum of all rating points generated by all 30-second commercials that the network can air during the broadcast year. GRP is typically calculated in the industry by multiplying the number of 30-second commercial slots with the rating points for each airing of a show and summing them over all airings of all shows during the broadcast year. Though the commercials that are aired can be of any length, a 30-second slot is used as a standard in computing the GRP. A 15-second slot is considered to deliver half the rating points of a 30second slot and is, consequently, charged half the price. Similarly, a 60-second slot is said to deliver twice the rating points of a 30-second slot and is sold at twice the price of a 30-second slot.

Since the show ratings are random and unknown at the time of the Upfront, the networks guarantee the delivery of certain number of rating points on their Upfront contracts. In fact, networks price sales contracts based on the guaranteed rating points using a negotiated price per rating point (or price per thousand viewers). If the network cannot deliver the guaranteed rating points in the time slots allocated to a customer, it has to air additional commercials for the customer to make up for the difference. On the other hand, if the shows perform much better than expected the network still needs to air the number of commercials in the Upfront contract which may lead to over delivering on the guaranteed rating points. This results in lost revenues as pricing in this industry is by the audience delivered. To avoid this situation, the networks generally over-promise ratings in the Upfront market. A television network can sell any amount of rating points up to the maximum potentially realizable value of the GRP to the advertisers. However, the GRP depends on the performance (or ratings) of the shows.

Under the scenario described above, a network television firm often faces the following decision problem: how much of the total expected GRP to sell during the Upfront market? We propose an analytical model to accomplish this. This problem has several interesting features. The gross rating 
Bollapragada, Srinivas, and Suman Mallik. "Managing On-air Ad Inventory in Broadcast Television." IIE Transactions 40.12

(2008): 1107-123. Publisher's official version: http://dx.doi.org/10.1080/07408170802323026. Open Access version:

http://kuscholarworks.ku.edu/dspace/.

Please share your stories about how Open Access to this item benefits you.

points of a network is random and depends on the performance of its shows. A network needs to make the decision about the rating points to be sold during the Upfront market before knowing whether a show will be a hit or a miss during the broadcast season. Rating points not sold during the Upfront market are sold on the Scatter market during the broadcast season at the prevailing price. Therefore, for any fixed amount of rating points sold during the Upfront market, a network will have more rating points to sell in a Scatter market when its shows are hits compared to when its shows are misses. Unlike the Upfront market, no rating points guaranty is offered during the Scatter market. The price per rating point during the Upfront market, or the Upfront price, is fixed (non-random) during the short duration of the Upfront market that usually lasts for about one to two weeks. In contrast, the price per rating point during the Scatter market, or the Scatter price, is random as several factors that influence it including the prevailing macro-economic conditions are not realized until the broadcast year begins. Thus, while making decisions about the Upfront inventory, a network needs to take into account the performance uncertainty of its shows as well as the price uncertainty of the Scatter market. In addition, a network has to pay a penalty when it is unable to meet its commitment for the number of viewers offered during the Upfront market. This happens when a network sells a large amount of rating points during the Upfront market and its shows turn out to be misses.

Selling commercial times through the Upfront and the Scatter markets has been the standard practice in the broadcast television industry since the mid-1970s. The volume of the Upfront market in broadcast television was $\$ 500$ million during the spring of 1979 (Source: The Gale group, 1999). For the year 2002, the volume of the Upfront market was $\$ 8.2$ billion with NBC leading the market with a sale of $\$ 2.7$ billion (Steinberg, 2003; Nelson \& Vranica, 2003). The Upfront market rose to an all time high of \$9.3 billion during 2003 (Chunovic, 2003), and remained essentially flat for 2004 and 2005 (Steinberg, 2004, 2005). The common practice among television networks is to sell about $60-80 \%$ of the total inventory (i.e., 60-80\% of the expected value of the GRP) of commercial times during the Upfront market. However, CBS deliberately sold less during the 2001's Upfront market, holding more for the Scatter market in anticipation of economic recovery following the crash of the stock market (Nelson \& Vranica, 2003). On the other hand, facing an uncertain Scatter market, each of the six broadcast networks (NBC, CBS, ABC, Fox, WB, and UPN) sold between $85 \%$ and $90 \%$ of total inventory during the strong Upfront of 2003 (Chunovic, 2003). The Scatter price, in general, is higher than the Upfront price. In fact, the Scatter prices have been higher than the Upfront prices for 11 out of the last 12 years (Lafayette and Friedman, 2004). On an average, the Scatter price is around 15\% higher than the Upfront price.

We propose an analytical model to study how much of the total ad inventory of a network should be sold during the Upfront market. Our model explicitly incorporates the performance uncertainty of the television shows as well as the revenue uncertainty of the Scatter market. We derive the conditions for 
Bollapragada, Srinivas, and Suman Mallik. "Managing On-air Ad Inventory in Broadcast Television." IIE Transactions 40.12

(2008): 1107-123. Publisher's official version: http://dx.doi.org/10.1080/07408170802323026. Open Access version:

http://kuscholarworks.ku.edu/dspace/.

Please share your stories about how Open Access to this item benefits you.

feasibility of the problem and characterize the optimal amount of rating points to sell in the Upfront market. Our model also provides insights on the current process of inventory allocation followed by the major networks. We provide an intuitive explanation for the current practice of selling $60-80 \%$ of the average GRP during the Upfront market. We also analyze other common strategies used by the networks in the Upfront market. We show that selling more in a strong Upfront cannot be a universally optimal strategy for a network. Our work makes important contributions to the operations management literature by providing explanations for the current practices in the broadcast television industry. In addition, it provides a quantitative methodology for the television networks to plan their Upfront markets. The practice in the industry thus far has been to determine the Upfront strategy qualitatively, based mostly on human judgment. To the best of our knowledge, no other paper has looked at the problem we address in this paper. Throughout the paper we refer to and quote from the popular business press extensively to demonstrate the relevance of our analytical results to the practitioners.

The remainder of this paper is organized as follows. The next section provides a review of the related literature. We describe our model in Section 3. Our analytical results are presented in Section 4. Section 5 presents a numerical study that complements our analytical findings. We describe the managerial implications and conclude the paper in Section 6.

\section{LITERATURE REVIEW}

The previous research on television industry is problem-driven. A bulk of the model-based literature deals with scheduling strategies for programs to maximize ratings. The typical examples are Goodhardt et al. (1975), Headen et al. (1979), Henry and Rinnie (1984), Webster (1985), Rust and Echambadi (1989), and Reddy et al. (1998). Sales planning and scheduling of television commercials has been studied by Bollapragada et al. (2002), Bollapragada, Bussieck, \& Mallik (2004), and Bollapragada \& Garbiras (2004). Jones and Koehler (2002) propose an auction mechanism for the Upfront sales problem where multiple buyers compete for the ad slots in the Upfront market by submitting bids. They propose a heuristic solution to the resulting integer program that provides a satisfactory solution within a short computation time. The focus of our work is fundamentally different from these studies. Araman and Popescu (2005) consider the stochastic revenue management problem for broadcast television networks. The focus of their study is to draw parallels between the airtime inventory allocation problems of television industry and the inventory/revenue management problems, while that of ours is to explain the observed practices in the broadcast television industry. As a result, our paper differs from theirs extensively on the approach taken as well as the results obtained.

Our work adds to the growing stream of literature in operations management that studies uncertainty in various forms. Our work comes closest to the papers studying advance booking discounts 
Bollapragada, Srinivas, and Suman Mallik. "Managing On-air Ad Inventory in Broadcast Television." IIE Transactions 40.12

(2008): 1107-123. Publisher's official version: http://dx.doi.org/10.1080/07408170802323026. Open Access version:

http://kuscholarworks.ku.edu/dspace/.

Please share your stories about how Open Access to this item benefits you.

(ABD). The ABD contract between a retailer and a supplier typically has two wholesale prices, a discounted price for the inventory purchased before the selling season and a regular price for replenishments during the selling season. The main source of uncertainty is the consumer demand. Many authors studied the ABD problem including Tang et al. (2004), Weng and Parlar (1999), McCardle, Rajaram and Tang (2004) and others. In addition to capturing the demand uncertainty by letting the Scatter market revenue to be a function of random variables, our work also incorporates supply uncertainty by considering the performance uncertainty of the television shows unlike in the ABD literature.

Several authors study a two-mode production problem in the context of demand and production planning where the first mode of production is relatively cheap and requires long leadtime while the second is expensive and offers quick turnaround. The manufacturer and/or the retailer receive updated information about the demand in between the two production modes. Fisher and Raman (1996) study the production decisions under such a scenario. This scenario does not arise in the process of selling commercial times broadcast television because of the short duration of the Upfront market which occurs well before the scatter market. In addition, the dynamics of the Upfront and the scatter market are different. A network guarantees the delivery of rating points in Upfront market while such guaranties are not offered in the scatter market. These features distinguish our work from Fisher and Raman (1996) and others studying secondary markets.

There is a vast body of literature on the revenue management for perishable assets such as the seats in a commercial airplane or the rooms in a hotel. The area of revenue management that comes closest to our work is capacity control where the total seat inventory in an aircraft or the rooms in a hotel is allocated among different fare classes. The researchers study this problem in considerable depth and details. Instead of reviewing this vast literature, we refer an interested reader to the excellent and up-todate reviews by Talluri and van Ryzin (2004) and Bitran and Caldentey (2003). Savin et al. (2005) consider the problem of revenue management in rental business with two customer classes where a single unit of capacity (an equipment, for example) can be used multiple times. The following feature distinguishes our work from this literature. The available inventory of seats/rooms is known (i.e., deterministic) in this literature. Our work, in contrast, treats the GRP (or the available inventory) as random. Bitran and Gilbert (1996) consider the problem of managing hotel reservations with uncertain arrivals. In addition to the customer demand, they treat the available supply (i.e., the inventory of available rooms) to be random because of stay-overs, no-shows, and cancellations. The focus of their work is whether to accept a guest that requires a room on a target day. The focus of our work, on the contrary, is to determine how much inventory to sell in Upfront. As a result, we differ extensively from Bitran and Gilbert (1996) in terms of problem formulation and the resulting insights. A few researchers 
Bollapragada, Srinivas, and Suman Mallik. "Managing On-air Ad Inventory in Broadcast Television." IIE Transactions 40.12

(2008): 1107-123. Publisher's official version: http://dx.doi.org/10.1080/07408170802323026. Open Access version:

http://kuscholarworks.ku.edu/dspace/.

Please share your stories about how Open Access to this item benefits you.

have studied the problem of group revenue management for hotels. This literature distinguishes between groups that book multiple rooms and the individual or transient customers booking single rooms. Group reservations are often made far in advance at a discounted rate. Schwartz and Cohen (2003) propose a model that can be used to calculate the lowest group room rate to which a hotel should agree. Choi (2006) considers the problem of whether to accept a group's offer for reservation. We note that the problem of group revenue management will be similar to our problem if a hotel is allowed to determine how many rooms will be sold to the groups at a discounted rate for a target date and that the available supply is random (because of no-shows, cancellations etc.). The published research on group revenue management is scarce and we do not know of any study that considers such a scenario. Rather, the literature considers the problem of whether to accept a group reservation of given size. In addition, none of the cited studies consider a random supply of rooms.

Finally, it is worth pointing out the difference between our work and the random yield literature. The fundamental assumption in the random yield literature is that the quantity of good units produced is always less than or equal to the number of starting units. On the contrary, our work allows both over- and under-delivery on the rating points sold in Upfront market. A reader is referred to Yano and Lee (1995) for a review of the random yield literature.

\section{THE MODEL}

Consider a single broadcast television network that is interested in determining the amount of rating points inventory to sell in the Upfront market. Throughout this paper, we will simply use the word "network" to denote a broadcast network television firm. The gross rating point (GRP) of a network during the broadcast season depends on the performance of its shows. Let $\tilde{X}$ be the random variable denoting the GRP available to the network. A realization of $\tilde{X}$ will be denoted by $x$. Throughout our paper we will use the symbol tilde to denote a random variable while a corresponding letter without the tilde will denote its realization. Let $f($.) and $F($.) denote the probability density function and the cumulative distribution function of $\tilde{X}$ respectively. We assume $F($.) to be continuously differentiable. The GRP of a network is affected by the performance rating of its shows as well as by the number of slots available for airing commercials. The former of the two is beyond the direct control of a network as it depends on a viewer's taste and preference. A network often tries to influence this by picking the "right" shows and by using scheduling strategies that consider schedules for other shows within the network as well as schedules of shows for competing networks. Several studies address these issues, as described in the Section 2 of our paper. The number of slots for airing commercials is standard across the industry (typically five commercial breaks for an hour of programming in the broadcast television). A network 
Bollapragada, Srinivas, and Suman Mallik. "Managing On-air Ad Inventory in Broadcast Television." IIE Transactions 40.12

(2008): 1107-123. Publisher's official version: http://dx.doi.org/10.1080/07408170802323026. Open Access version:

http://kuscholarworks.ku.edu/dspace/.

Please share your stories about how Open Access to this item benefits you.

cannot single-handedly increase the number of commercial slots within a program for the fear of alienating the viewers. A network decides on number of commercial breaks to use as well as its scheduling strategies separately at a strategic level much before making decisions about the Upfront inventory. As a result, we will treat $\tilde{X}$, the GRP, to be an exogenous random variable in our model. The firm sells $x_{u} \geq 0$ amount of rating points in the Upfront market and commits to airing commercials in $n_{u}\left(x_{u}\right)$ slots out of the available $N$ slots during the broadcast year. An Upfront contract guaranties the delivery of the promised rating points as well as the predefined minimum number of slots $\left(n_{u}\right)$ to customers. Given the show ratings are random, let $\tilde{Y}\left(x_{u}\right)$ be the GRP delivered in the $n_{u}\left(x_{u}\right)$ slots promised to the customers during the Upfront. Note that the random variable $\tilde{Y}$ is a function of $n_{u}\left(x_{u}\right)$. However, the number of slots promised, $n_{u}$, is not a decision variable (we elaborate more on this matter later and justify it in Proposition 1). As a result, we will write $\tilde{Y}$ to be simply a function of $x_{u}$ and denote it by $\tilde{Y}\left(x_{u}\right)$. Obviously, the random variable $\tilde{Y}\left(x_{u}\right)$ is highly correlated with the random variable $\tilde{X}$ and that $\tilde{X}$ is always larger than $\tilde{Y}\left(x_{u}\right)$. Let $y$ be a realization of $\tilde{Y}\left(x_{u}\right)$. If $y \leq x_{u}$, the network needs to air additional commercials (over the promised numbers $n_{u}$ ) to make up for the ratings shortfall of $x_{u}-y$. On the other hand if $y>x_{u}$, i.e. if the shows perform better than expected, the network still needs to air commercials in the promised $n_{u}$ slots and, consequently, ends up over-delivering on its guarantees. Since the network is obligated to air commercials in all $n_{u}$ slots included in the Upfront contract, an over delivery represents a lost revenue opportunity for the network. To avoid such a situation, networks in practice promise more rating points than they expect to deliver in the time slots sold during the Upfront market. As a reader will see in Proposition 1, this is indeed an optimal strategy for a network. Our model formulation will capture these tradeoffs explicitly without making $n_{u}$ a decision variable for our model.

Let $r_{u}\left(x_{u}\right)$ denote the Upfront revenue for the network when $x_{u} \geq 0$ amount of rating points are sold during the Upfront. We assume that $r_{u}(0)=0$. We also assume that $\frac{d r_{u}\left(x_{u}\right)}{d x_{u}} \geq 0$ and that $\frac{d^{2} r_{u}\left(x_{u}\right)}{d x_{u}^{2}} \leq 0$, implying $r_{u}($.$) is increasing and concave in x_{u}$. Our objective here is to have a pricedependent demand function (downward slopping). A concave revenue function allows us to achieve this objective without assuming anything specific about the shape of the demand function for the Upfront market. Let $r_{s}(\tilde{X}, \tilde{\omega}, \tilde{\theta})$ denote the Scatter revenue. The scatter revenue is a function of three random quantities: the gross rating point $\tilde{X}$, the availability of the rating points in the Scatter market $\tilde{\omega}$, and a 
Bollapragada, Srinivas, and Suman Mallik. "Managing On-air Ad Inventory in Broadcast Television." IIE Transactions 40.12

(2008): 1107-123. Publisher's official version: http://dx.doi.org/10.1080/07408170802323026. Open Access version:

http://kuscholarworks.ku.edu/dspace/.

\section{Please share your stories about how Open Access to this item benefits you.}

random parameter $\tilde{\theta}$. We assume that the expected value of the Scatter revenue is increasing with the realized gross rating point. This assumption is consistent with the observation in practice that price per rating point is higher when the shows of a network are hits compared to when the shows are misses. The rating points available to sell during the Scatter market, $\tilde{\omega}$, depends on $x_{u}$ and the realized values of $\tilde{X}$, $\tilde{Y}\left(x_{u}\right)$ and is given by:

$$
\tilde{\omega}= \begin{cases}\tilde{X}-x_{u}, & \text { for } \tilde{X} \geq x_{u}, \tilde{Y}<x_{u} \\ \tilde{X}-\tilde{Y}\left(x_{u}\right), & \text { for } \tilde{X} \geq x_{u}, \tilde{Y} \geq x_{u} . \\ 0, & \text { for } \tilde{X}<x_{u}\end{cases}
$$

Recall that the random variable $\tilde{Y}$ denotes the rating points delivered in the promised $n_{u}$ airings, while $\tilde{X}$ denotes the GRP. . If $x \geq x_{u}$ and $y \leq x_{u}$, the network needs to air additional commercials (over the promised numbers $n_{u}$ ) to make up for the ratings shortfall. Therefore, after delivering on the rating points guaranty, it will only have $x-x_{u}$ rating points available for sale in the scatter market. On the other hand if $x \geq x_{u}$ and $y>x_{u}$, i.e., if the shows perform better than expected, the network still needs to air commercials in the promised $n_{u}$ slots and, consequently, ends up over-delivering on its guarantees. Under this scenario, the network will have $x-y$ rating points available for sale in the scatter market. Since the network is obligated to air all $n_{u}$ commercials included in the Upfront contract, an over delivery represents a lost revenue opportunity for the network.

Similar to the assumption about Upfront revenue, we will assume that the Scatter revenue is increasing and concave in the availability of rating points in the Scatter market. We will also assume that $r_{s}(x, 0, \theta)=0, \forall x, \theta$. Finally, the random parameter $\tilde{\theta}$ captures the effect of exogenous parameters on the scatter revenue. We mentioned in Section 1 that the Scatter market price often exhibits a correlation with the prevailing macroeconomic conditions. The parameter $\tilde{\theta}$ might capture such effects. For notational convenience, let $m_{u}\left(x_{u}\right)=\frac{d r_{u}\left(x_{u}\right)}{d x_{u}}$ denote the marginal revenue from the Upfront market and $m_{s}(\omega)=\frac{d}{d \omega} E_{X, \omega, \theta}\left[r_{s}(\tilde{X}, \tilde{\omega}, \tilde{\theta})\right]$ denote the marginal value of the expected revenue from the Scatter market. 
Bollapragada, Srinivas, and Suman Mallik. "Managing On-air Ad Inventory in Broadcast Television." IIE Transactions 40.12

(2008): 1107-123. Publisher's official version: http://dx.doi.org/10.1080/07408170802323026. Open Access version:

http://kuscholarworks.ku.edu/dspace/.

Please share your stories about how Open Access to this item benefits you.

A network pays a penalty whenever the rating points sold in the Upfront market, $x_{u}$, exceeds the realized value of the gross rating point $\tilde{X}$. Let $p_{o}>0$ be the penalty per rating point for over-selling during the Upfront market. The revenue of the network is given by:

$$
\pi\left(x_{u}\right)=r_{u}\left(x_{u}\right)+\left\{\begin{array}{l}
r_{s}(x, \omega, \theta), \text { for } x \geq x_{u} \\
-p_{o}\left(x_{u}-x\right), \text { for } x<x_{u}
\end{array},\right.
$$

where, $\omega$ is given by (1). The first term in (2) represents the Upfront revenue while the second term represents the scatter revenue. When $x \geq x_{u}$, the availability of rating points for Scatter sales is determined by equation (1). On the other hand, when $x<x_{u}$, even the entire GRP realized is not sufficient to meet the commitments made during the Upfront. As a result the network pays a unit penalty cost of $p_{o}$ on the shortfall. We assume that $p_{o}>m_{s}(0)$ and $p_{o}>m_{u}(0)$. The first assumption ensures that a network must first honor the rating points promised during the Upfront before making any Scatter sales. This situation always occurs in practice as a network can reliably predict the gross rating points by looking at the performances of its shows during the first few weeks of any broadcast year. Moreover, Scatter sales occur throughout the broadcast year as Upfront contracts are being fulfilled. The second assumption ensures that a network cannot make money simply by over-promising in the Upfront market. The value of this parameter is specified in the Upfront contract. We describe the timing of the events of our model next. The Upfront typically occurs in the month of May, almost four months before the start of the broadcast season, when a network makes decisions about how much rating points to sell in the Upfront $\left(x_{u}\right)$. Substantial uncertainty about the GRP, $\tilde{X}$, exists at that point. The scatter market occurs throughout during the broadcast season (mid-September through May of the following year). The uncertainty about the show performances during the Scatter market is much smaller when compared to the uncertainties of the Upfront market as the show ratings do not vary significantly during the broadcast year. Both the networks and the advertisers have good estimates about the rating points of shows once the broadcast year has begun. Moreover, though the commercial times sold in the Scatter market are priced based on the rating points that they are expected to deliver, they do not carry any guaranty on the rating points. Therefore we assume the following timing of events in the paper. A network first decides $x_{u}$ in the Upfront. The GRP ( $\tilde{X}$ ) and the random parameter $\tilde{\theta}$ for the Scatter market are realized next. Finally, the Scatter sales are made based on the market price and available rating points. It is worth emphasizing that the objective of our paper is to study the amount of rating points to be sold during the Upfront. Given the timing of events described, we are not concerned about the dynamic allocation of rating points based on continuously realizable values of the GRP. 
Bollapragada, Srinivas, and Suman Mallik. "Managing On-air Ad Inventory in Broadcast Television." IIE Transactions 40.12

(2008): 1107-123. Publisher's official version: http://dx.doi.org/10.1080/07408170802323026. Open Access version:

http://kuscholarworks.ku.edu/dspace/.

Please share your stories about how Open Access to this item benefits you.

The objective of a network is to determine the amount of rating points to be sold in the Upfront market. A network often exhibits risk averseness while making such decisions. Broadcast networks have to commit to a large portion of their costs in developing the programming (entertainment shows) well before the broadcast season begins. By being risk averse, a network can have a large part of its revenues booked before the broadcast season begins. We model this behavior of the network by introducing a chance constraint that ensures that its revenues are greater than a pre-specified value $R$ with a large probability $\psi$. The problem facing a network is as follows.

\section{Problem P1}

$\underset{x_{u} \geq 0}{\operatorname{Maximize}} \mathrm{z}=E \pi$,

Subject to: $\Psi\left(x_{u}\right)=\operatorname{Pr} .\{\pi \geq R\} \geq \psi$.

Our objective, in this paper, is to maximize the expected profit of a network. However, the short-term cost of a network is largely a fixed cost, in the form of programming development cost. In addition, the total cost of a network does not change with respect to our decision variable $x_{u}$, the quantity of rating points sold in the Upfront market. As a result, it is sufficient for us to seek a $x_{u}$ that maximizes the expected revenue. Problem P1, thus, maximizes the expected revenue of the network subject to the fact that the revenue must be greater than or equal to a pre-specified value $R$ with a probability of at least $\psi$. The chance constraint (4) models the risk-averse behavior of the network. Note that our model formulation in (1)-(4) does not require $n_{u}$ to be a decision variable. This is consistent with our observation in practice that the price of an Upfront deal (and hence the revenue for a network) depends only on the promised rating points. Equations (1) and (2) capture all constraints faced by a network for committing to $n_{u}$ airings without explicitly making $n_{u}$ a decision variable. Finally, it is important to note that the current practice in the industry is to make decisions qualitatively, rather than using any formal models.

\section{RESULTS AND ANALYSES}

We begin our discussion by establishing the concavity of the expected value of the revenue function of the network defined by equation (2).

Lemma 1: The expected revenue function $z=E \pi$, where $\pi$ is defined by (2) is concave in $x_{u}$, the amount of rating points sold during the Upfront. 
Bollapragada, Srinivas, and Suman Mallik. "Managing On-air Ad Inventory in Broadcast Television." IIE Transactions 40.12

(2008): 1107-123. Publisher's official version: http://dx.doi.org/10.1080/07408170802323026. Open Access version:

http://kuscholarworks.ku.edu/dspace/.

Please share your stories about how Open Access to this item benefits you.

The proof of Lemma 1, as well as those of other results, is included in the appendix. Establishing a desirable property like the concavity of the expected revenue helps us in our analyses throughout this paper.

We stated in the previous section that the common practice among the networks is to overpromise rating points during the Upfront. The next proposition shows that this is an optimal strategy for any expected-revenue-maximizing network.

Proposition 1: For any given amount of rating point sold in Upfront $\left(x_{u}\right)$,

(a) it is optimal for an expected-revenue-maximizing network to allocate as few slots $\left(n_{u}\right)$ as possible during the Upfront.

(b) the probability of a network over delivering on its promised rating points increases as the mean of $\tilde{Y}$ increases.

(c) the probability of a network over delivering on its promised rating points increases as the variance of $\tilde{Y}$ increases if amount of rating points sold is more than the mean of $\tilde{Y}$; otherwise the probability of over-delivery decreases with the variance of $\tilde{Y}$.

Proposition 1(a) states that a network should promise as few slots as possible during the Upfront implying over-promising during the Upfront is an optimal strategy for a network. It is, indeed, a common practice among all six major broadcast networks to over-promise on the rating points during the Upfront season. The larger the amount by which a network over promises the smaller is the probability of over-delivery. This behavior is consistent with Proposition 1. Buyers of commercial times normally accept a certain amount of inflation in the promised rating points since they are compensated by extra commercials to make up for the shortfall in meeting the guarantees. Proposition 1(a) also implies that we have not lost any generality of our model by not making $n_{u}$ a decision variable. Propositions 1 (b) and 1(c) state how the probability of over delivery is affected by the mean and variance of $\tilde{Y}$. When a network enters a broadcast season with many new shows, resulting in a higher variance of $\tilde{Y}$, the chance of leaving money on the table increases whenever the amount of rating points sold in the Upfront exceeds the expected value of $\tilde{Y}$. For example, the shows "Apprentice” on NBC and "Desperate Housewives" on ABC performed much better than expected when they were first introduced and both networks ended up leaving some money on the table in their first seasons. 
Bollapragada, Srinivas, and Suman Mallik. "Managing On-air Ad Inventory in Broadcast Television." IIE Transactions 40.12

(2008): 1107-123. Publisher's official version: http://dx.doi.org/10.1080/07408170802323026. Open Access version:

http://kuscholarworks.ku.edu/dspace/.

Please share your stories about how Open Access to this item benefits you.

We are now ready to discuss the optimal solution of problem P1. A brief description of a special case of problem P1, where we ignore the chance constraint in (4), is warranted first. These results are presented in Section 4.1. The results for the problem $\mathbf{P 1}$ are presented in Section 4.2.

\subsection{A Special Case of Problem P1}

This sub-section considers a risk neutral firm by ignoring the constraint (4) in the Problem P1. We call this as Problem P0.

\section{Problem P0}

$$
\underset{x_{u} \geq 0}{\operatorname{Maximize}} \mathrm{z}=E \pi
$$

The following proposition describes our result.

Proposition 2: Let $h(x, y, \theta)$ denote the joint probability density function of the random variables $\tilde{X}, \tilde{Y}\left(x_{u}\right)$ and $\tilde{\theta}$. The optimal solution to problem $\mathbf{P 0}$ satisfies the condition:

$$
\begin{aligned}
m_{u}\left(x_{u}\right)=p_{o} F\left(x_{u}\right) & -\int_{\theta} \int_{y=0}^{x_{u}} \int_{x=x_{u}}^{\infty} \frac{\partial}{\partial x_{u}}\left[r_{s}\left(x, x-x_{u}, \theta\right) h(x, y, \theta)\right] d x d y d \theta \\
& -\int_{\theta} \int_{y=x_{u}}^{\infty} \int_{x=x_{u}}^{\infty} \frac{\partial}{\partial x_{u}}\left[r_{s}(x, x-y, \theta) h(x, y, \theta)\right] d x d y d \theta .
\end{aligned}
$$

It is important for us to characterize the optimal solution for problem P0 as several of our results for problem P1 will depend on this quantity. Proposition 2 characterizes this optimal solution in terms of a critical fractile of the joint distribution of $\tilde{X}, \tilde{Y}\left(x_{u}\right)$, and $\tilde{\theta}$. We will denote this solution as $\left.x_{u}^{*}\right|_{P 0}$. The intuition behind Proposition 2 is similar to that of the newsvendor optimal quantity. The quantity $\left.x_{u}^{*}\right|_{P 0}$ represents the tradeoff between under- and over-delivery of the promised rating points.

Note that the problem P0 represents a risk neutral network. However, a network is rarely risk neutral in practice. As a result, the solution for problem P0 is often unable to explain the observed behavior of a network in practice. Since the Scatter prices, in general, are higher than the Upfront prices, it is optimal for a risk neutral network to sell more in the Scatter market than in the Upfront market. However, the exact opposite behavior is observed in practice. Problem P0, nevertheless, remains a useful benchmark and we will be referring to $\left.x_{u}^{*}\right|_{P 0}$, the optimal quantity a risk-neutral network sells in the Upfront, several times throughout the remainder of this paper. 
Bollapragada, Srinivas, and Suman Mallik. "Managing On-air Ad Inventory in Broadcast Television." IIE Transactions 40.12

(2008): 1107-123. Publisher's official version: http://dx.doi.org/10.1080/07408170802323026. Open Access version:

http://kuscholarworks.ku.edu/dspace/.

Please share your stories about how Open Access to this item benefits you.

\subsection{Analysis of Problem P1}

We will now analyze problem $\mathbf{P 1}$ and develop some useful properties and results. We begin our discussion by exploring the properties of the chance constraint in equation (4). This analysis will come in handy in characterizing the optimal solution of problem P1. Using conditional probability the expression $\Psi\left(x_{u}\right)$ in (4) can be written as follows.

$$
\Psi\left(x_{u}\right)=\operatorname{Pr}\{\pi \geq R\}=\operatorname{Pr}\left\{\pi \geq R \mid x \leq x_{u}\right\} \operatorname{Pr}\left\{x \leq x_{u}\right\}+\operatorname{Pr}\left\{\pi \geq R \mid x>x_{u}\right\} \operatorname{Pr}\left\{x>x_{u}\right\}
$$

Using equations (A2) and (A5) from the Appendix, the expression for $\Psi\left(x_{u}\right)$ can further be simplified as follows.

$$
\Psi\left(x_{u}\right)=\left\{\begin{array}{ll}
\Psi_{1}\left(x_{u}\right), & x_{u} \leq r_{u}^{-1}(R) \\
\Psi_{2}\left(x_{u}\right), & x_{u}>r_{u}^{-1}(R)
\end{array},\right.
$$

Where,

$$
\begin{aligned}
& \Psi_{1}\left(x_{u}\right)=\operatorname{Pr}\left\{r_{s}(\tilde{X}, \tilde{\omega}, \tilde{\theta}) \geq R-r_{u}\left(x_{u}\right)\right\}, \text { and } \\
& \Psi_{2}\left(x_{u}\right)=1-F\left(R / p_{o}+x_{u}-r_{u}\left(x_{u}\right) / p_{o}\right) .
\end{aligned}
$$

The following proposition describes the structural properties of $\Psi\left(x_{u}\right)$.

Proposition 3: In the region $x_{u} \geq r_{u}^{-1}(R), \Psi\left(x_{u}\right)$ is the largest at $x_{u}=r_{u}^{-1}(R)$.

Proposition 3 describes the structure of the function $\Psi\left(x_{u}\right)$. The result is quite intuitive. The quantity $r_{u}^{-1}(R)$ denotes the amount of inventory a firm needs to sell to achieve the target revenue entirely from the Upfront market. Thus, selling more than $r_{u}^{-1}(R)$ amount of rating points in the Upfront does not increase the chance of achieving the target revenue any more. On the other hand, it might increase the chances of incurring a penalty for not delivering on the promised rating points. As a result, in the region $x_{u} \geq r_{u}^{-1}(R), \Psi\left(x_{u}\right)$ is the largest at $x_{u}=r_{u}^{-1}(R)$. Note that the result is very general in nature as we have not assumed anything about the distributions of the random variables $\tilde{X}, \tilde{Y}\left(x_{u}\right)$, or $\tilde{\theta}$ beyond the differentiability of respective CDFs. Neither have we assumed anything about the specific functional forms for $r_{u}($.$) and r_{s}($.) beyond concavity. In addition, Proposition 3 has significant implications as stated by the following corollary. 
Bollapragada, Srinivas, and Suman Mallik. "Managing On-air Ad Inventory in Broadcast Television." IIE Transactions 40.12 (2008): 1107-123. Publisher's official version: http://dx.doi.org/10.1080/07408170802323026. Open Access version: http://kuscholarworks.ku.edu/dspace/.

\section{Please share your stories about how Open Access to this item benefits you.}

Corollary 1: The maximum value of $\Psi\left(x_{u}\right)$ lies in the region $\left[0, r_{u}^{-1}(R)\right]$. Furthermore, if $\left.x_{u}^{*}\right|_{P 0} \leq r_{u}^{-1}(R)$, then the optimal solution for problem $\mathbf{P 1}$ lies in the region $\left[0, r_{u}^{-1}(R)\right]$. Otherwise, the optimal solution for problem $\mathbf{P 1}$ lies in the region $\left[0,\left.x_{u}^{*}\right|_{P 0}\right]$.

The quantities $\left.x_{u}^{*}\right|_{P 0}$ and $r_{u}^{-1}(R)$ play important roles in Corollary 1 as well as in our subsequent results. As a result, these two quantities warrant a brief discussion. The quantity $\left.x_{u}^{*}\right|_{P 0}$ maximizes the expected revenue of a network (i.e. solves problem P0) by optimally balancing the over- and under-delivery of promised rating points. The quantity $r_{u}^{-1}(R)$ is the amount of rating points a network needs to sell in the Upfront if it wishes to book the target revenue of $R$ entirely from the Upfront sales. Our extensive numerical experiments using realistic values of the problem parameters suggest that the relationship $\left.x_{u}^{*}\right|_{P 0} \leq r_{u}^{-1}(R)$ is likely to hold is practice. Intuitively, given the concave nature of the Upfront revenue function, booking the target revenue entirely from the Upfront will require a substantial amount of rating points to be sold in Upfront, which is likely to be more than the expected-revenue-maximizing quantity.

When the relationship $\left.x_{u}^{*}\right|_{P 0} \leq r_{u}^{-1}(R)$ holds, per Corollary 1, the optimal solution for problem P1 lies in the region $\left[0, r_{u}^{-1}(R)\right]$. Corollary 1 allows us to restrict our searches for the optimal solution of problem $\mathbf{P 1}$ to a specific region for any arbitrary distribution of the random variables $\tilde{X}, \tilde{Y}\left(x_{u}\right)$, and $\tilde{\theta}$. It is easy to see from the formulation of $\mathbf{P 1}$ that given specific distributions of $\tilde{X}, \tilde{Y}\left(x_{u}\right)$, and $\tilde{\theta}$, problem $\mathbf{P 1}$ may not be feasible for certain combination of the parameters $R$ and $\psi$. The next proposition describes a sufficient condition for feasibility of problem P1, as well as an upper bound for it.

Proposition 4: A sufficient condition for the feasibility of problem $P 1$ is $r_{u}^{-1}(R) \leq F^{-1}(1-\psi)$. Moreover, the upper bound on the optimal solution to problem P1 is given by $\left.x_{u}^{*}\right|_{P 1} \leq \operatorname{Min}\left\{F^{-1}(1-\psi), \operatorname{Max}\left[r_{u}^{-1}(R),\left.x_{u}^{*}\right|_{P 0}\right]\right\}$.

Proposition 4 is a useful guiding tool for any practitioner involved in the planning Upfront sales event. It states that as the value of target revenue $R$ increases, the target probability $\psi$ must decrease. The first part of the proposition describes a sufficient condition for feasibility of problem P1. The elegance of the 
Bollapragada, Srinivas, and Suman Mallik. "Managing On-air Ad Inventory in Broadcast Television." IIE Transactions 40.12

(2008): 1107-123. Publisher's official version: http://dx.doi.org/10.1080/07408170802323026. Open Access version:

http://kuscholarworks.ku.edu/dspace/.

Please share your stories about how Open Access to this item benefits you.

result lies in easily calculable parameters. It is also clear from Proposition 4 that as $\psi$ increases, $R$ must decrease for $\mathbf{P 1}$ to remain feasible.

We next characterize the optimal solutions for problem P1 and develop useful properties of the optimal solutions. As a reader will see, our analyses explain many of the observed practices followed in this industry. The following Lemma is useful in characterizing the optimal solution of $\mathbf{P 1}$.

Lemma 2: If $\Psi\left(x_{u}\right)$ is a decreasing function of $x_{u}$ at a point $\bar{x}_{u}$ in the region $\left[0, r_{u}^{-1}(R)\right]$, then it cannot be increasing at any $x_{u} \geq \bar{x}_{u}$ in the region $\left[0, r_{u}^{-1}(R)\right]$.

Theorem 1 (Optimal Solution for P1): Assume problem P1 is feasible. When $\Psi\left(\left.x_{u}^{*}\right|_{P 0}\right) \geq \psi$, $\left.x_{u}^{*}\right|_{P 1}=\left.x_{u}^{*}\right|_{P 0}$. Otherwise consider the case when:

(a) $\Psi\left(x_{u}\right)$ is increasing in $x_{u}$ in the region $\left[0, r_{u}^{-1}(R)\right]$. If $\left.x_{u}^{*}\right|_{P 0} \leq r_{u}^{-1}(R)$, then $\left.x_{u}^{*}\right|_{P 1}$ is given by the solution of the equation $\Psi_{1}\left(x_{u}\right)=\psi$, otherwise $\left.x_{u}^{*}\right|_{P 1}$ solves $\Psi_{2}\left(x_{u}\right)=\psi$.

(b) $\Psi\left(x_{u}\right)$ is decreasing in $x_{u}$ in the region $\left[0, r_{u}^{-1}(R)\right]$. If $\left.x_{u}^{*}\right|_{P 0} \leq r_{u}^{-1}(R)$, then $\left.x_{u}^{*}\right|_{P 1}$ is given by the solution of the equation $\Psi_{1}\left(x_{u}\right)=\psi$, otherwise if $\Psi\left(r_{u}^{-1}(R)\right) \geq \psi$, then $\left.x_{u}^{*}\right|_{P 1}$ solves $\Psi_{2}\left(x_{u}\right)=\psi$, else $\left.x_{u}^{*}\right|_{P 1}$ solves $\Psi_{1}\left(x_{u}\right)=\psi$.

(c) $\Psi\left(x_{u}\right)$ is not monotone in $x_{u}$ in the region $\left[0, r_{u}^{-1}(R)\right]$. The optimal solution for problem $\mathbf{P 1},\left.x_{u}^{*}\right|_{P 1}$, can be found by a bisection search.

Theorem 1 characterizes the optimal solution for problem P1. Section 5 will provide ample numerical examples to further develop insights on the properties of the optimal solution. It is obvious that the optimal solutions of problems $\mathbf{P 1}$ and $\mathbf{P 0}$ are identical when $\Psi\left(\left.x_{u}^{*}\right|_{P 0}\right) \geq \psi$. This scenario is likely to happen when a network has not set the target revenue $R$ and target probability $\psi$ aggressively. When the cost of program development is high, a network will set a high value of the target revenue and the target probability. Under this scenario, the relationship $\Psi\left(\left.x_{u}^{*}\right|_{P 0}\right) \geq \psi$ is unlikely to hold and the optimal solution of $\mathbf{P 1}$ depends on whether the function $\Psi\left(x_{u}\right)$ is increasing or decreasing (or both) in the region $\left[0, r_{u}^{-1}(R)\right]$ as well as on the problem parameters. Lemma 2 implies that when $\Psi\left(x_{u}\right)$ is both increasing and decreasing in the region $\left[0, r_{u}^{-1}(R)\right]$, it cannot first be decreasing and then increasing. This property allows us the check for whether the function $\Psi\left(x_{u}\right)$ is increasing or decreasing (or both) in the region 
Bollapragada, Srinivas, and Suman Mallik. "Managing On-air Ad Inventory in Broadcast Television." IIE Transactions 40.12

(2008): 1107-123. Publisher's official version: http://dx.doi.org/10.1080/07408170802323026. Open Access version:

http://kuscholarworks.ku.edu/dspace/.

\section{Please share your stories about how Open Access to this item benefits you.}

$\left[0, r_{u}^{-1}(R)\right]$ for any given problem parameters by simply evaluating the derivative $\partial \Psi_{1}\left(x_{u}\right) / \partial x_{u}$ at the two points $x_{u}=0$ and $x_{u}=r_{u}^{-1}(R)$.

Theorem 1 provides a precise quantitative guideline to a practitioner on how much inventory to sell during the Upfront. As described in Section 1, the practice in the industry thus far has been to make this decision qualitatively, based mostly on human judgments. A quantitative methodology provides an enormous improvement opportunity over a qualitative judgment. A large network like NBC will typically book revenues worth more that $\$ 2.5$ billion during the Upfront. Thus, even a one percentage point deviation from the optimal expected revenue will represent millions of dollars.

Theorem 1 has additional implications as well. It is interesting to note that choosing $x_{u}=r_{u}^{-1}(R)$ will lead to a feasible solution of P1under many circumstances. For example, it is easy to see that when the condition of Theorem 1(a) is satisfied, choosing $x_{u}=r_{u}^{-1}(R)$ will always result in a feasible solution of problem P1. Under the conditions of Theorem 1(b) and 1(c), choosing $x_{u}=r_{u}^{-1}(R)$ will result in a feasible solution of $\mathbf{P} \mathbf{1}$ as long as the relationship $\Psi\left(r_{u}^{-1}(R)\right) \geq \psi$ holds. The current practice in the industry, as we mentioned earlier in the paper, is to make decisions qualitatively. Thus, in absence of any formal quantitative model, $x_{u}=r_{u}^{-1}(R)$ might be an attractive choice for a practicing manager making decisions about Upfront inventory. In practice, many networks choose the value of the target revenue $R$ such that $r_{u}^{-1}(R)$ falls in the range of $60-80 \%$ of the expected value of the gross rating point. This might explain the widely observed practice of selling $60-80 \%$ of the expected value of the available inventory in the Upfront. In absence of a formal model, a practicing manger may also inadvertently attempt to maximize the probability of hitting the target revenue (i.e. maximize $\Psi\left(x_{u}\right)$ ) instead of solving problem P1. This behavior might arise when the program development cost is very high and that a risk-averse manager would like to book a substantial part of the revenue with very high probability. It is easy to see that under the condition of Theorem 1(a), choosing $x_{u}=r_{u}^{-1}(R)$ will maximize the probability of hitting the target revenue $R$ (i.e. maximize the function $\Psi\left(x_{u}\right)$ ). Therefore for a network making qualitative decision about the Upfront inventory, $x_{u}=r_{u}^{-1}(R)$, or a value of $x_{u}$ around $r_{u}^{-1}(R)$, is an attractive choice not only when it is attempting to solve $\mathbf{P 1}$ but also when it is inadvertently attempting to maximize the probability of hitting the target revenue instead of solving problem P1. This might provide an additional explanation for the practice of selling $60-80 \%$ of the expected value of the available ad inventory by all six major broadcast networks. A network probably has arrived at this solution by trial and error. 
Bollapragada, Srinivas, and Suman Mallik. "Managing On-air Ad Inventory in Broadcast Television." IIE Transactions 40.12 (2008): 1107-123. Publisher's official version: http://dx.doi.org/10.1080/07408170802323026. Open Access version: http://kuscholarworks.ku.edu/dspace/.

Please share your stories about how Open Access to this item benefits you.

How do the optimal solutions for $\mathbf{P 0}$ and $\mathbf{P 1}$ compare? The following Corollary provides an answer.

Corollary 2: If $\left.x_{u}^{*}\right|_{P 0} \leq r_{u}^{-1}(R)$ and $\Psi\left(x_{u}\right)$ is an increasing function of $x_{u}$ in the region $\left[0, r_{u}^{-1}(R)\right]$, then for any given set of problem parameters, $\left.x_{u}^{*}\right|_{P 0} \leq\left. x_{u}^{*}\right|_{P 1}$.

As mentioned earlier, $r_{u}^{-1}(R)$ denotes the amount of inventory a network needs to sell to achieve the target revenue entirely from the Upfront market. Our numerical studies indicate that $\Psi\left(x_{u}\right)$ is an increasing function of $x_{u}$ unless the target revenue $R$ is very high and the target probability $\psi$ is small. Thus, the conditions of Corollary 2 are likely to be satisfied for any realistic choice of $R$ and $\psi$. Under the assumptions of this corollary, the optimal quantity to sell in the Upfront market goes up as a network becomes more risk averse.

Proposition 5: The maximum value of $\Psi\left(x_{u}\right)$ is independent of the penalty cost $p_{o}$. Furthermore, if $\left.x_{u}^{*}\right|_{P 0} \leq r_{u}^{-1}(R)$ then the optimal solution of problem $\mathbf{P 1}$ is also independent of the penalty cost $p_{o}$.

The discussion following Corollary 1 describes why the relationship $\left.x_{u}^{*}\right|_{P 0} \leq r_{u}^{-1}(R)$ is likely to hold for realistic values of the problem parameters. When this relationship holds, it is interesting to note that a network can simply ignore the penalty cost while making its decision about Upfront inventory. The intuitive explanation for this result is as follows. When $\left.x_{u}^{*}\right|_{P 0} \leq r_{u}^{-1}(R)$, by Corollary 1, the optimal solutions of problem $\mathbf{P 1}$ lies in the region $\left[0, r_{u}^{-1}(R)\right]$. For any $x_{u}$ in this region, the relationship $r_{u}\left(x_{u}\right) \leq R$ holds. The penalty cost becomes an issue for a network when the entire GRP is not enough to meet the rating points committed during the Upfront. Under such a situation, the Scatter revenue for the network is zero and the revenue of the network is no longer more than the target revenue R. This implies that the optimal solution of $\mathbf{P 1}$ cannot be dependent on the penalty cost. By Corollary 1, the maximum value of $\Psi\left(x_{u}\right)$ lies in the region $\left[0, r_{u}^{-1}(R)\right]$. Note from equations (7) and (8) that $\Psi\left(x_{u}\right)$, is independent of the penalty cost $p_{o}$ in this region. As a result, the maximum value of $\Psi\left(x_{u}\right)$ is also independent of the penalty cost.

We next look at the sensitivity of the optimal solution of problem P1 with respect to a stronger/weaker Upfront season. Per industry terminology, the higher the Upfront price, the stronger an 
Bollapragada, Srinivas, and Suman Mallik. "Managing On-air Ad Inventory in Broadcast Television." IIE Transactions 40.12

(2008): 1107-123. Publisher's official version: http://dx.doi.org/10.1080/07408170802323026. Open Access version:

http://kuscholarworks.ku.edu/dspace/.

Please share your stories about how Open Access to this item benefits you.

Upfront Season. We formally define Upfront 2 to be stronger than Upfront 1 if and only if $r_{u}^{1}\left(x_{u}\right) \leq r_{u}^{2}\left(x_{u}\right), \forall x_{u}$. The following proposition describes our result.

Proposition 6: When all other parameters remain constant, $\left.x_{u}^{*}\right|_{P 1}$ is non-increasing in a stronger Upfront if $\left.x_{u}^{*}\right|_{P 1} \geq\left. x_{u}^{*}\right|_{P 0}$, while it is non-decreasing in a stronger Upfront if $\left.x_{u}^{*}\right|_{P 1}<\left.x_{u}^{*}\right|_{P 0}$.

Proposition 6 describes an interesting tradeoff. Given the concavity of our revenue functions for Upfront and scatter markets, each successive unit of inventory brings in lower marginal returns. When the relationship $\left.x_{u}^{*}\right|_{P 1} \geq\left. x_{u}^{*}\right|_{P 0}$ holds, a network is already selling a substantial amount (i.e. more than $\left.x_{u}^{*}\right|_{P 0}$ ) of inventory in the Upfront. Thus selling more may not bring in a substantial incremental contribution. In addition, the stronger Upfront allows the network to achieve the same Upfront revenue of a weaker Upfront with less inventory. Thus, the optimal quantity to sell in the Upfront decreases in a stronger Upfront when $\left.x_{u}^{*}\right|_{P 1} \geq\left. x_{u}^{*}\right|_{P 0}$. On the other hand, when $\left.x_{u}^{*}\right|_{P 1}<\left.x_{u}^{*}\right|_{P 0}$, a network is not selling a substantial amount of inventory in the Upfront and can take advantage of the stronger Upfront by making additional inventory available during the Upfront. Proposition 6, thus, represents the tradeoff between a strong Upfront and a decreasing marginal contribution of each additional unit of inventory.

Corollary 2 provides a sufficient condition for the relationship $\left.x_{u}^{*}\right|_{P 1} \geq\left. x_{u}^{*}\right|_{P 0}$ to hold. Our extensive numerical experimentation indicates that the relationship $\left.x_{u}^{*}\right|_{P 1} \geq\left. x_{u}^{*}\right|_{P 0}$ is likely to hold in practice for almost all realistic values of the target revenue $\mathrm{R}$ and the target probability $\psi$. The intuitive explanation for this is as follows. The quantity $\left.x_{u}^{*}\right|_{P 0}$ is the expected revenue maximizing choice for a risk neutral network. For any realistic values of the target revenue $R$ and the probability $\psi$, a risk-averse network solving problem $\mathbf{P 1}$ is likely to sell more inventory in the Upfront. Our numerical experiments indicate that the relationship $\left.x_{u}^{*}\right|_{P 1}<\left.x_{u}^{*}\right|_{P 0}$ is only likely to hold under the unrealistic scenario where the target revenue $R$ is very large while the target probability $\psi$ is small (Section 6 of the paper describes a numerical study to complement our analytical findings. Using the baseline parameter values from this study, we needed the target revenue $R$ to be more than the optimal expected revenue of problem $\mathbf{P 0}$ and $\psi$ $<25 \%$ in order to have $\left.x_{u}^{*}\right|_{P 1}<\left.x_{u}^{*}\right|_{P 0}$ ). Proposition 6 thus implies that a risk averse network solving problem P1 should sell less inventory in a strong Upfront. Section 6 of our paper will elaborate on the managerial implications of this important finding. 
Bollapragada, Srinivas, and Suman Mallik. "Managing On-air Ad Inventory in Broadcast Television." IIE Transactions 40.12

(2008): 1107-123. Publisher's official version: http://dx.doi.org/10.1080/07408170802323026. Open Access version:

http://kuscholarworks.ku.edu/dspace/.

Please share your stories about how Open Access to this item benefits you.

Proposition 7: When the standard deviation of the distribution of GRP as well as all other parameters remains constant, the optimal solution of problem $\mathbf{P 1},\left.x_{u}^{*}\right|_{P 1}$, is non-increasing in the mean of the distribution of GRP if $\left.x_{u}^{*}\right|_{P 1} \geq\left. x_{u}^{*}\right|_{P 0}$, while it is non-decreasing in the mean of the distribution of GRP if $\left.x_{u}^{*}\right|_{P 1}<\left.x_{u}^{*}\right|_{P 0}$.

Proposition 7 describes the sensitivity of the optimal solution of problem $\mathbf{P 1}$ with respect to the mean of the gross rating point. It is worth noting that it may not always be possible to vary the mean of a distribution independent of its standard distribution (exponential distribution, for example). Proposition 7 , thus, applies to only those distributions of GRP where it is possible to change the mean independently of the standard deviation. The intuition behind this result similar to that of Proposition 6. When the mean of GRP increases while the variance is held constant, the Scatter market becomes more attractive to a network. Proposition 7 represents the tradeoff between decreasing marginal revenue in the scatter market and an attractive scatter market. When $\left.x_{u}^{*}\right|_{P 1} \geq\left. x_{u}^{*}\right|_{P 0}$, the network is making less inventory available in the scatter market (as it is selling a substantial amount in the Upfront). Thus, making more inventory available in the scatter market (by reducing $\left.x_{u}^{*}\right|_{P 1}$ ) allows a network to take advantage of the attractive scatter market without a substantial reduction in marginal revenue. However, the opposite effect becomes more dominant when $\left.x_{u}^{*}\right|_{P 1}<\left.x_{u}^{*}\right|_{P 0}$ and a network reduces the inventory availability in the scatter market by selling more in the Upfront. It is hard to analytically characterize the sensitivity of the optimal solution of P1 with respect to the standard deviation of the GRP when all other parameters are held constant. Our numerical study described in Section 5 will provide insights on this. Finally, it is worth mentioning that the sensitivity behavior of the optimal solution of problem $\mathbf{P 1}$ with respect to the mean of the random parameter $\tilde{\theta}$ when its standard deviation is held constant is similar to that of the mean of gross rating point as long as a higher realization of $\theta$ is associated with higher scatter revenue, i.e., $\partial r_{s} / \partial \theta \geq 0$. The proof of this result is similar to that of Proposition 7.

Section 4 describes the analytical solution of problem P1. Our analysis throughout this section indicates that the two quantities $r_{u}^{-1}(R)$ and $\left.x_{u}^{*}\right|_{P 0}$ play very important roles in our model. The former of the two denotes the amount of inventory a firm needs to sell to achieve the target revenue entirely from 
Bollapragada, Srinivas, and Suman Mallik. "Managing On-air Ad Inventory in Broadcast Television." IIE Transactions 40.12

(2008): 1107-123. Publisher's official version: http://dx.doi.org/10.1080/07408170802323026. Open Access version:

http://kuscholarworks.ku.edu/dspace/.

Please share your stories about how Open Access to this item benefits you.

the Upfront market, while the later denotes the optimal inventory a risk-neutral network sells in the Upfront. The next section presents a numerical study to complement our analytical findings.

\section{NUMERICAL STUDY}

In this section we present a numerical study to complement our analytical findings. We use the following revenue functions for the Upfront and Scatter markets throughout this Section: $r_{u}\left(x_{u}\right)=p_{u} x_{u}\left(1-0.003 x_{u}\right)$ and $\tilde{r}_{s}(\tilde{X}, \omega, \theta)=\tilde{p}_{s}(\tilde{X}, \theta) . \omega .(1-0.004 \omega)$, where, $p_{u}$ and $\tilde{p}_{s}($.$) are the$ Upfront and the Scatter prices respectively. Note that consistent with our discussion earlier, the Scatter price $\tilde{p}_{s}($.$) depends both on the gross rating point and the random environmental parameter \theta$. We choose $\tilde{Y}\left(x_{u}\right)=0.9 x_{u}(\tilde{X} / E(\tilde{X}))$ which implies that the network over promised ratings by $10 \%$ on average (since $E(\tilde{Y})=0.9 x_{u}$ ). All random variables in our model are assumed to follow normal distributions. We use the following values as the baseline parameters in our numerical study.

$p_{u}=100, p_{o}=140, \psi=90 \%, E(\tilde{X})=100, S D(\tilde{X})=10, E\left(\tilde{p}_{s}\right)=115+3 \cdot \frac{\tilde{X}-E(\tilde{X})}{S D(\tilde{X})}, S D\left(\tilde{p}_{s}\right)=35$, $R=6000,6500$, and 7000 .

Our numerical study explores the optimal solution to problem $\mathbf{P 1}$ and its sensitivity with respect to various problem parameters not discussed in our analytical study. We solved problem P1 using MATLAB. We computed the optimal value of $x_{u}$ using simulation as follows. We first generated 100,000 instances for each of the random variables $\tilde{X}$ and $\tilde{p}_{s}($.$) . Using these values we computed the$ expected revenue, $z$ and the probability that the revenue is greater than the target value $R$ for a chosen value of $x_{u}$. By varying the value of $x_{u}$, we compute $z$ and $\Psi($.$) as a function of x_{u}$. The value of $x_{u}$ for which $z$ is maximized is the solution for problem P0. The value of $x_{u}$ for which the function $\Psi\left(x_{u}\right) \geq \psi$ and $z$ is maximized is the optimal quantity to sell in the Upfront market for problem $\mathbf{P 1}$.

The remainder of this Section is organized as follows. Section 5.1 discusses the sensitivities of the optimal solution and the optimal objective function values of problem P1 with respect to various problem parameters. Section 5.2 studies the robustness of the expected revenue with respect to the inventory decisions in the Upfront market.

\subsection{Sensitivity of the Optimal Solution of P1 with respect to Problem Parameters}

Figures 1(a), 2(a), and 3(a) describe the optimal solution of problem P1 under various representative values of the problem parameters. Recall that the mean of the distribution of the gross 
Bollapragada, Srinivas, and Suman Mallik. "Managing On-air Ad Inventory in Broadcast Television." IIE Transactions 40.12

(2008): 1107-123. Publisher's official version: http://dx.doi.org/10.1080/07408170802323026. Open Access version:

http://kuscholarworks.ku.edu/dspace/.

Please share your stories about how Open Access to this item benefits you.

rating point is set to 100 as our baseline parameter. As a result, the value of optimal amount of inventory to sell in these figures is also the percentage of inventory to sell in the Upfront. These figures give a reader an idea about the optimal percentage of inventory to sell during the Upfront under various representative parameter values. Figures 1(a) and 1(b), respectively, describe the sensitivity of the optimal

solution of $\mathbf{P 1},\left.x_{u}^{*}\right|_{P 1}$, and its optimal objective function value $z^{*}$ with respect to the standard deviation of the scatter price for different values of the target revenue $R$. Here we vary the standard deviation of the scatter price from 5 to 50, while all other parameters remain constant at their respective baseline values. The two figures confirm the intuition that as the standard deviation of the scatter price increases, the scatter market becomes less attractive to a network resulting in an increase in the optimal quantity to sell during the Upfront and a decrease in the optimal expected revenue. Figures 2(a) and 2(b), respectively, describe the sensitivity of the optimal solution of $\mathbf{P 1}$ and its optimal objective function value with respect to the mean of the scatter price, $\mu_{p_{s}}$. As the mean of Scatter price increases while all other parameter remains constant, the Scatter market becomes more attractive to a network. As a result, the optimal solution of $\mathbf{P 1}$ is non-increasing in the mean of Scatter price (Figure 2a). Figure 2(b), expectedly, shows that the optimal objective function value for both problem P1 increase as mean of the scatter price increases. We summarize our discussion so far in the following Observation.

Observation 1: When all other parameters are held constant, the optimal solution of problem P1 is nonincreasing with respect to the mean of the scatter price and non-decreasing with respect to the standard deviation of the scatter price.

We next look at the sensitivity of the optimal solution of problem P1 with respect to the standard deviation of the distribution of the gross rating point $\tilde{X}$. Proposition 7 describes the sensitivity of the optimal solution of problem P1 with respect to the mean of the gross rating point. Therefore, it is sufficient for us to study the sensitivity with respect to the standard deviation here. Figures 3(a) and 3(b), respectively, describe our results for the optimal solution and the optimal objective function values. The intuition behind Figure 3(a) is quite interesting. When the target revenue is high $(R=7000)$, as the standard deviation of the gross rating point increases, it becomes more and more difficult to satisfy the chance constraint in (4) with smaller values of $x_{u}$; resulting in an increase in the optimal solution of problem P1. On the other hand, when the target revenue is small, a network may be able to satisfy the chance constraint in (4) with small values of $x_{u}$ as the standard deviation of the gross rating point increases. As a result, the optimal solution of $\mathbf{P 1}$ goes down. In this scenario, leaving money on the table 
Bollapragada, Srinivas, and Suman Mallik. "Managing On-air Ad Inventory in Broadcast Television." IIE Transactions 40.12

(2008): 1107-123. Publisher's official version: http://dx.doi.org/10.1080/07408170802323026. Open Access version:

http://kuscholarworks.ku.edu/dspace/.

Please share your stories about how Open Access to this item benefits you.

by over-delivering on the promised rating points becomes an issue and a network tries to reduce this by selling less rating points in the Upfront.

Observation 2: When all other parameters are held constant, the optimal solution of problem $\mathbf{P 1}$ is nonincreasing in the standard deviation of the GRP distribution for smaller values of the target revenue $R$ while it is non-decreasing in the standard deviation of the GRP distribution for higher values of $R$.

\subsection{Computation of Expected Revenues under Different Scenarios}

Our objective in this sub-section is two-fold. First, we would like to characterize the value of using both the Upfront and the Scatter market to a network. To accomplish this, we will compare the optimal expected revenue of problem $\mathbf{P 1}$ with the expected revenue when a network makes no inventory available in the Upfront. Second, we will study the robustness of expected revenue with respect to the inventory decisions made during the Upfront.

Consider a scenario where a network sells all of its airtime in the Scatter market. Clearly, the expected revenue of a network selling all airtime in the Scatter market is $E_{X, \omega, \theta}\left[r_{s}(\tilde{X}, \tilde{\omega}, \tilde{\theta})\right]$. We calculated the value of this expression using the revenue functions and the problem parameters described at the beginning of Section 5. Figure 4(a) compares the optimal expected revenue of $\mathbf{P 1}$ to the expected revenue from selling everything in the Scatter market as a function of the mean of GRP distribution. As seen from the plot, the optimal expected revenues of problem $\mathbf{P 1}$ is higher than the expected revenue from an all-Scatter sale for all values of the mean of GRP distribution. The result is intuitive. When a network makes its entire inventory available in the Scatter market, because of the concavity of the revenue function, the scatter price falls, resulting in a reduction of the expected revenue for the network. On the other hand, by selling a considerable part of the inventory in the Upfront (in problem P1), a network effectively restricts the supply in the Scatter, resulting in a higher Scatter price and a higher total expected revenue. This result holds for all values of mean of the GRP distribution studied. Figures 4(b) and 4(c), respectively, compare the optimal expected revenue of $\mathbf{P 1}$ to the expected revenue of selling everything in scatter as a function of the standard deviation of the GRP distribution and the mean of the scatter price distribution. The intuition behind these figures is identical to that behind Figure 4(a). Figures 4(a)-(c) suggest that a using both the Upfront and the Scatter market results in a higher expected revenue for network than using the scatter market alone. The concave nature of the revenue functions contribute to this result. Finally, Figure 5 describes how the expected revenue deviates from its optimal value as the Upfront inventory changes from its optimal value.

We have described the optimal solution of problem P1 under the assumption of Normal distribution. Our findings complement our analytical findings by describing the sensitivity of the optimal 
Bollapragada, Srinivas, and Suman Mallik. "Managing On-air Ad Inventory in Broadcast Television." IIE Transactions 40.12 (2008): 1107-123. Publisher's official version: http://dx.doi.org/10.1080/07408170802323026. Open Access version: http://kuscholarworks.ku.edu/dspace/.

\section{Please share your stories about how Open Access to this item benefits you.}

solution of P1 with respect to various problem parameters. Our extensive numerical experiments also involved repeating all calculations under the assumption that both $\tilde{p}_{s}(\tilde{X}, \theta)$ and $\tilde{X}$ follow the beta distribution. These results are qualitatively similar to those of the Normal Distribution and are available from the authors under request. We have also tested the robustness of our numerical findings using exponential revenue functions of the following form: $r_{u}\left(x_{u}\right)=p_{u} x_{u} \exp \left(-\gamma_{1} x_{u}\right)$, and $\tilde{r}_{s}(\tilde{X}, \omega, \theta)=\tilde{p}_{s}(\tilde{X}, \theta) \cdot \omega \cdot \exp \left(-\gamma_{2} \omega\right), \gamma_{1}, \gamma_{2}>0$, under normal and beta distribution assumptions. The results are again qualitatively similar and that Observations 1 and 2 continue to hold.

\section{SUMMARY AND MANAGERIAL IMPLICATIONS}

Allocating the inventory of commercial rating points between the Upfront and the Scatter markets is an important decision facing any broadcast television network. The Upfront market represents a sizable proportion of the total advertising revenue for a television network. In this paper, we studied the problem of optimal inventory allocation between the Upfront and the Scatter markets. We proposed an optimization model with a chance constraint that explicitly incorporated the performance uncertainty of the television shows as well as the revenue uncertainty of the Scatter market. Starting with a very general framework, we derived the structural properties of the optimization problem and characterized the optimal solution. We discussed several useful properties of the optimal solution including its sensitivity with respect to a stronger Upfront, and the mean of the distribution of the gross rating point. We also address the issue of over-delivering on the promised rating points. Our numerical study complements our analytical findings and provides additional sensitivity results of the optimal solution of problem P1. Our work has the following implications for managers.

Our work represents the first attempt to bring quantitative methodologies in planning the Upfront event for a television network. The current practice in the industry is to make decisions based on qualitative human judgments. In line with our observation in the industry, we incorporated the riskaverseness of a network by including a chance constraint. Our work provides both descriptive and prescriptive implications for a manager involved in planning the Upfront event for a network.

Our model (Theorem 1) provides specific prescriptive recommendations to a manager on the amount of rating points to sell during the Upfront while specifically taking into account the risk preference of the network. A quantitative methodology provides an enormous improvement opportunity over a qualitative judgment. A large network like NBC will typically book revenues worth more that \$2.5 billion during the Upfront. Thus, even a one percentage point deviation from the optimal expected revenue will represent millions of dollars. This underscores the importance of using quantitative 
Bollapragada, Srinivas, and Suman Mallik. "Managing On-air Ad Inventory in Broadcast Television." IIE Transactions 40.12 (2008): 1107-123. Publisher's official version: http://dx.doi.org/10.1080/07408170802323026. Open Access version: http://kuscholarworks.ku.edu/dspace/.

\section{Please share your stories about how Open Access to this item benefits you.}

methodologies in making the decisions for Upfront inventory. On the descriptive side, our model provides an explanation for the widely observed practice of selling $60-80 \%$ of the total inventory during the Upfront event. The discussion following Theorem 1 shows that choosing $x_{u}=r_{u}^{-1}(R)$ results in a feasible solution to Problem P1 under many circumstances. In addition, this choice might maximize the probability of hitting the target revenue $R$ (i.e. maximize the function $\Psi\left(x_{u}\right)$ ). In absence of a formal model, a risk-averse manager might inadvertently do this instead of solving P1. This might explain why it is common for all six major broadcast networks to sell $60-80 \%$ of the total inventory during the Upfront. We also show in Proposition 5 that when $\left.x_{u}^{*}\right|_{P 0} \leq r_{u}^{-1}(R)$, the optimal solution of problem P1 is independent of the penalty cost. This is a useful insight for a manager planning the Upfront event. This might explain why a network is often more concerned about leaving money on the table by overdelivering on the promised rating points than paying penalty for falling short on the promised rating points.

Per Proposition 7, the optimal amount of rating points to sell in Upfront increases as the mean of GRP decreases as long as the relationship $\left.x_{u}^{*}\right|_{P 1} \geq\left. x_{u}^{*}\right|_{P 0}$ holds. We have discussed following Proposition 6 that the relationship $\left.x_{u}^{*}\right|_{P 1} \geq\left. x_{u}^{*}\right|_{P 0}$ is likely to hold for any realistic choices of the target revenue and the target probability. NBC, facing a 17\% rating slump during the 2004 broadcast year, sold only $70 \%$ of the inventory during the Upfront of 2005, while it sold about 83\% during the Upfront of 2004 (Higgins, 2005). Proposition 7 suggests that this might, indeed, have been a good strategy for NBC.

Not all shows of a network are entirely new in any broadcast year. Popular shows often run over multiple seasons. The famed show "Seinfeld", for example, ran for nine broadcast seasons. There are other examples in recent years (CBS in 2004-2005 broadcast year) when a network started a new broadcast year with a stable line up of hit shows and only a few new shows. Under such a circumstance, a network will have a very good estimate of the mean and standard deviation of the GRP (high mean, low standard deviation) and will set a high value of target revenue $R$. Per Observation 2, for a high value of target revenue, the optimal Upfront inventory should decrease as the standard deviation of GRP decreases, while per Proposition 7, the optimal Upfront inventory should decrease as the mean of GRP increases as long as the relationship $\left.x_{u}^{*}\right|_{P 1} \geq\left. x_{u}^{*}\right|_{P 0}$ holds. Therefore, a network with a stable lineup of hit shows will make lesser amount of the ad inventory available for the Upfront market. The buyers, on the other hand, will be highly interested in buying commercial times on such a network. Given our concave revenue functions, a network will command a higher Upfront price. This was the case with CBS during the Upfront market of 2004. We quote from a The Wall Street Journal (Steinberg, 2004). 
Bollapragada, Srinivas, and Suman Mallik. "Managing On-air Ad Inventory in Broadcast Television." IIE Transactions 40.12 (2008): 1107-123. Publisher's official version: http://dx.doi.org/10.1080/07408170802323026. Open Access version: http://kuscholarworks.ku.edu/dspace/.

Please share your stories about how Open Access to this item benefits you.

According to a person familiar with the matter, CBS expects to secure about $\$ 2.4$ billion in advertising commitments for its coming prime-time schedule, up from about \$2.2 billion in 2003. CBS was able to convince marketers to pay double-digit percent increases in the price it charges to reach 1,000 viewers, while UPN was able to secure price increases in the $9 \%$ range, the person said.

An article in Television Week (Lafayette and Friedman, 2004) provides further details about why CBS was able to negotiate double-digit percent increases in Upfront price. We again quote.

Coming off a strong season and with a stable programming lineup enhanced by a third edition of its "CSI" franchise, CBS was waiting to do deals that would bring the double-digit price increases that CBS Television President Leslie Moonves talked about before the Upfront began.

The Fox network also faced a similar situation recently. Fox sold less inventory during the Upfront of 2005 (Steinberg, 2005) after leading all networks among 18- to 49-year-old viewers for the season 20042005 (Grego and Lisotta, 2005). This is, again, consistent with problem P1 as long as the relation $\left.x_{u}^{*}\right|_{P 1} \geq\left. x_{u}^{*}\right|_{P 0}$ holds. Our work, thus, not only explains the observed behavior in the industry, but also provides specific quantitative recommendations on quantity to sell during the Upfront season for various "what-if” scenarios.

We mentioned in Section 1 that facing an uncertain Scatter after the slow Upfront seasons of 2001 and 2002, each of the six major broadcast networks sold between 85\% and 90\% of total ad inventory during the strong Upfront season of 2003 (Chunovic, 2003). Similarly, when ABC negotiated a 4-6\% hike in the Upfront price in 2005 over 2004, it sold between $78 \%$ and 83\% of the total ad inventory in 2005, as opposed to 75-80\% during the Upfront of 2004 (Steinberg, 2005). Thus, it appears that several networks pursued the policy of selling more in a strong Upfront. Per Proposition 6, this cannot be a universally optimal strategy. In fact, Proposition 6 underscores that for any reasonable and realistic values of the problem parameters, a network should sell less in a strong Upfront. Our analyses provide specific quantitative recommendations on when to sell more in a strong Upfront and how much inventory to make available in a stronger/weaker Upfront. This can, again, be useful guiding tool for a practicing manager.

Proposition 1 of our paper states that the probability of leaving money on the table increases as the show performances become hard to predict. It happens when a network enters a broadcast season with new shows. Under such a situation, per Figure 3(a), it is optimal for a revenue-maximizing network to sell more in the Upfront only if the target revenue is set very aggressively. Otherwise, a firm should sell less during the Upfront. This was the case with ABC during the Upfront of 2004 when it underestimated the impact of the first seasons of the shows "Desperate Housewives" and "Lost" and sold more inventory in the Upfront, leaving money on the table. Our suspicion is that ABC probably did not set its target revenue very aggressively, which made the practice of selling more in the Upfront sub-optimal per Figure 3(a). 
Bollapragada, Srinivas, and Suman Mallik. "Managing On-air Ad Inventory in Broadcast Television." IIE Transactions 40.12

(2008): 1107-123. Publisher's official version: http://dx.doi.org/10.1080/07408170802323026. Open Access version:

http://kuscholarworks.ku.edu/dspace/.

Please share your stories about how Open Access to this item benefits you.

The Wall Street Journal commented, “ABC learned last year that it pays to take risks in programming” (Steinberg, 2005).

Selling commercial times through the Upfront and the Scatter markets has been the common practice since the 1970s. Our numerical results discussed in Section 5.2 indicate that this process is indeed valuable to a risk-averse network. In addition to booking a significant chunk of revenues from the Upfront market, this two-stage selling process allows a network to derive higher expected revenue compared to selling everything in the scatter market. The advertisers and media buyers too find this process to be attractive as it allows them to purchase commercial times with guaranteed rating points at a price which is often lower than the Scatter market price. Thus, by selling the bulk of the available inventory in the Upfront, a network is probably helping to build strong customer relationship as well.

Our work adds to the growing stream of literature in operations management that studies uncertainty in various forms. The distinguishing feature of our model is the dual uncertainty regarding the Scatter revenue and the gross rating point. Our results are distribution-independent and remain valid for any distributions of the Scatter revenue and the gross rating point. Our models make important contributions to the operations management literature by extending the revenue management framework to random supply problems. In addition, it provides explanations for the current practices in the broadcast television industry and a new quantitative tool to the TV Networks in planning for Upfront market. To the best of our knowledge, no other paper has looked at the dynamics of selling rating points in the broadcast television industry before.

Like any other work in operations management, our work is not free from assumptions. We have assumed concave revenue functions. This assumption is reasonable and is consistent with price-dependent demand functions. Our current work focuses on the decision problem faced by a single firm only. Studying the strategic interactions between firms at the Upfront and Scatter markets in a game theoretic context would be a useful extension of our current work.

\section{REFERENCES}

Araman, V.F., I. Popescu. 2005. Stochastic Revenue Management Models for Media Broadcasting. Working Paper, New York University.

Bitran, G.R., S.M. Gilbert. 1996. Managing Hotel Reservations with Uncertain Arrivals. Operations Research. 41(1), 35-49.

Bitran, G., R. Caldentey. 2003. An Overview of Pricing Models for Revenue Management. Manufacturing \& Service Operations Management. 5(3), 203-230.

Bollapragada, S., H.Cheng, M. Phillips, M. Scholes, T. Gibbs, M. Humphreville. 2002. NBC's Optimization Systems Increase its Revenues and Productivity. Interfaces. 32(1). 
Bollapragada, Srinivas, and Suman Mallik. "Managing On-air Ad Inventory in Broadcast Television." IIE Transactions 40.12

(2008): 1107-123. Publisher's official version: http://dx.doi.org/10.1080/07408170802323026. Open Access version:

http://kuscholarworks.ku.edu/dspace/.

Please share your stories about how Open Access to this item benefits you.

Bollapragada, S., M.R. Bussieck, S. Mallik. 2004. Scheduling Commercial Videotapes in Broadcast Television. , Operations Research, 52(5), 679-689.

Bollapragada, S., M. Garbiras. 2004. Scheduling Commercials on Broadcast Television. Operations Research, 52(3), 337-345.

Choi, S. 2006. Group Revenue Management: A model for Evaluating Group Profitability. Cornell Hotel and Restaurant Administration Quarterly. 47(3), 260-271.

Chunovic, L. 2003. Upfront a record 9.3 Bil. Television Week. Vol. 20(21), p. 25, May 26, 2003.

Fisher, M., A. Raman. 1996. Reducing the Cost of Demand Uncertainty Through Accurate Response to Early Sales. Operations Research. 44(1), 87-99

Goodhardt, G.J., A.S.C. Ehrenberg, M.A. Collins. 1975. The Television Audience: Patterns of Viewing. Saxon House, Westmead, England.

Grego, M., C. Lisotta. 2005. Fox Plots Its Upfront From Catbird Seat. Television Week. Vol. 24(20), p. 40, May 16, 2005.

Headen, R.S., J.E. Klompmaker, R.T. Rust. 1979. The Duplication of Viewing Law and Television Media Scheduling Evaluation. Journal of Marketing Research. 16, 333-340.

Henry, M.D., H.J. Rinne. 1984. Predicting Program Shares in New Time Slots. Journal of Advertising Research. 24(2), 9-17.

Higgins, J.M. 2005. ABC: An Upfront Spoiler? Broadcasting \& Cable. 135(28), 6, July 11, 2005.

Jones, J., G.J. Koehler. 2002. Combinatorial Auctions using Rule-Based Bids. Decision Support Systems. 34(1), 59-74.

Khouja, M. 1999. The single-period (news-vendor) problem: literature review and suggestions for future research. Omega, The International Journal of Management Science. 27, 537-553.

Lafayette, J., W. Friedman. 2004. CBS and ABC Holdouts in Slow Upfront. Television Week. 23(24), 0-1.

McCardle, K.F., K. Rajaram, C.S. Tang. 2004. Advance Booking Discount Programs under retail Competition. Management Science. 50(5), 701-708.

Nelson, E., S. Vranica. 2003. Demand Is Strong for Time on TV. The Wall Street Journal. March 10, 2003.

Reddy, S.K., J.E. Aronson, A. Stam. 1998. SPOT: Scheduling Programs Optimally for Television. Management Science. 44(1), 83-102.

Rust, R.T., N.V. Echambadi. 1989. Scheduling Network Television Programs: A Heuristic Audience Flow Approach to Maximizing Audience Share. Journal of Advertising. 18(2) , 11-18.

Savin, S.V., M.A. Cohen, N. Gans, Z. Katalan. 2005. Capacity Management in Rental Businesses with Two Customer Bases. Operations Research. 53(4), 617-631.

Schwartz, Z., E. Cohen. 2003. Hotel Revenue Management with Group Discount Room Rates. Journal of Hospitality \& Tourism Research. 27(1), 24-47.

Simon, H. 1982. ADPLUS: An advertising Model with Wear out and Pulsation. Journal of Marketing Research. 19, 352-363.

Steinberg, B. 2003. TV’s ‘Upfront’ Looks Like a Hit. The Wall Street Journal. May 12, 2003. 
Bollapragada, Srinivas, and Suman Mallik. "Managing On-air Ad Inventory in Broadcast Television." IIE Transactions 40.12

(2008): 1107-123. Publisher's official version: http://dx.doi.org/10.1080/07408170802323026. Open Access version:

http://kuscholarworks.ku.edu/dspace/.

Please share your stories about how Open Access to this item benefits you.

Steinberg, B. 2005. Not Desperate for Ad Commitments; Thanks to Strong Ratings And Subdued Strategy, ABC Wraps Up Its 'Upfront' Sale. The Wall Street Journal. June 1, 2005.

Talluri, T.T.., G.J. van Ryzin. 2004. The theory and Practice of Revenue Management. Kluwer Academic Publishers.

Tang, C.S., K. Rajaram, A. Alptekinoglu, J.Ou. 2004. The benefits of Advance Booking Discount Programs: Model and Analysis. Management Science. 50(4), 465-478.

Webster, J.G. 1985. Program Audience Duplication: A Study of Television Inheritance Effects. Journal of Broadcasting \& Electronic Media. 29(2), 121-133.

Weng, K., M. Parler. 1999. Integrating Early Sales with Production Decisions: Analysis and Insights. Forthcoming, IIE Transactions.

Yano, C.A., H.L. Lee. 1995. Lot Sizing With Random Yields: A review. Operations Research. 43(2), 311-334. 
Please share your stories about how Open Access to this item benefits you.

\section{APPENDIX : PROOFS OF RESULTS}

\section{Proof of Lemma 1}

For notational convenience, let us write $z=E_{X, Y, \theta} \pi=r_{u}\left(x_{u}\right)+E_{X, Y, \theta} q\left(x_{u} ; \tilde{X}, \tilde{Y}, \tilde{\theta}\right)$. Using equations (1) and (2), clearly,

$$
q\left(x_{u} ; x, y, \theta\right)=\left\{\begin{array}{l}
r_{s}\left(x, x-x_{u}, \theta\right), \text { for } x \geq x_{u}, y<x_{u} \\
r_{s}(x, x-y, \theta), \text { for } x \geq x_{u}, y \geq x_{u} \\
-p_{o}\left(x_{u}-x\right), \text { for } x<x_{u}
\end{array} .\right.
$$

We want to establish the concavity of $z$ with respect to $x_{u}$. Given $r_{u}\left(x_{u}\right)$ is concave in $x_{u}$, and that the expectation operator preserves concavity (see, for example, proof of Theorem 1 in Fisher and Raman, 1996), it is sufficient to establish the concavity of $q\left(x_{u} ; x, y, \theta\right)$ with respect to $x_{u}$.

Consider two values of $x_{u}, x_{u 1}$ and $x_{u 2}$, with $x_{u 1}<x_{u 2}$. Depending upon the random variables $\tilde{X}$ and $\tilde{Y}$ the following six scenarios are possible.

1. $x \geq x_{u 1}, x_{u 2} ; y \geq x_{u 1}, x_{u 2}$

2. $x \geq x_{u 1}, x_{u 2} ; x_{u 1} \leq y \leq x_{u 2}$

3. $x \geq x_{u 1}, x_{u 2} ; y<x_{u 1}, x_{u 2}$

4. $x_{u 1} \leq x \leq x_{u 2} ; x_{u 1} \leq y \leq x_{u 2}$

5. $x_{u 1} \leq x \leq x_{u 2} ; y \leq x_{u 1}, x_{u 2}$

6. $x<x_{u 1}, x_{u 2}$

We will show that $q\left(x_{u} ; x, y, \theta\right)$ is concave in each of the six scenarios described above. Consider Case 2 above for example.

$$
\begin{aligned}
& q\left(x_{u 1} ; x, y, \theta\right)=r_{s}(x, x-y, \theta) \geq r_{s}\left(x, x-x_{u 2}, \theta\right)=q\left(x_{u 2} ; x, y, \theta\right) \text {. } \\
& \left.\frac{\partial q\left(x_{u} ; x, y, \theta\right)}{\partial x_{u}}\right|_{x_{u}=x_{u 1}}=0 \text {, as } x_{u 1} \leq y \\
& \geq-\left.\frac{\partial r_{s}(x, \omega, \theta)}{\partial \omega}\right|_{\chi_{u}=x_{u 2}} \text {, as } r_{s}(.) \text { is increasing in } \omega \\
& =\left.\frac{\partial q\left(x_{u} ; x, y, \theta\right)}{\partial x_{u}}\right|_{x_{u}=x_{u 2}}
\end{aligned}
$$

Therefore, $q\left(x_{u 1} ; x, y, \theta\right)$ is concave in $x_{u}$. The proofs for other five cases are similar.

\section{Proof of Proposition 1}

(a) We want to show that for a given $x_{u}$, if $n_{u_{1}} \leq n_{u_{2}}$ then $E \pi_{1} \geq E \pi_{2}$, where $\pi$ is the revenue of a network as defined in equation (1). We will let $\tilde{Y}_{1}$ and $\tilde{Y}_{2}$ denote the GRP realized in $n_{u_{1}}$ and $n_{u_{2}}$ slots respectively. Given $n_{u_{1}} \leq n_{u_{2}}$, the random variable $\tilde{Y}_{2}$ is stochastically larger than the random variable $\tilde{Y}_{1}$ 
Bollapragada, Srinivas, and Suman Mallik. "Managing On-air Ad Inventory in Broadcast Television." IIE Transactions 40.12 (2008): 1107-123. Publisher's official version: http://dx.doi.org/10.1080/07408170802323026. Open Access version: http://kuscholarworks.ku.edu/dspace/.

\section{Please share your stories about how Open Access to this item benefits you.}

. (note that we will use the standard definitions of stochastic dominance, as given in any standard stochastic processes textbook. See, for example, p. 404 of Stochastic Processes by Sheldon Ross, $2^{\text {nd }}$ Edition, John Wiley, 1996). Therefore, for any given $\tilde{X}, \tilde{X}-\tilde{Y}_{1}$ is stochastically larger than $\tilde{X}-\tilde{Y}_{2}$. Using Proposition 9.1.2 on p. 405 of Stochastic Processes by Sheldon Ross, $2^{\text {nd }}$ Edition, and noting that $r_{s}(\eta)$ is an increasing function of $\eta$ for any realization of $\tilde{r}_{s}$, the following relationship holds for any realization of $\tilde{r}_{s}$. $E\left[r_{s}\left(\tilde{X}-\tilde{Y}_{1}\right)\right] \geq E\left[r_{s}\left(\tilde{X}-\tilde{Y}_{2}\right)\right]$. From equation (1), this implies that $E \pi_{1} \geq E \pi_{2}$.

(b) Let $\mu$ and $\sigma$ denote the mean and the SD of $\tilde{Y}$. Define $\tilde{\varepsilon}=(\tilde{Y}-\mu) / \sigma$.

Prob. of over-delivery $=\operatorname{Pr}\left\{\tilde{Y}>x_{u}\right\}=\operatorname{Pr}\left\{\tilde{\varepsilon}>\left(x_{u}-\mu\right) / \sigma\right\}=1-F_{\varepsilon}\left(\left(x_{u}-\mu\right) / \sigma\right)$. Therefore, the probability of over-delivery increases as $\mu$ increases or as $\sigma$ increases and $x_{u} \geq \mu$.

\section{Proof of Proposition 2}

By Lemma 1, the expected revenue is concave. Therefore, the first-order conditions are sufficient to characterize the optimal solution of P0. Using equations (1), (2),

$$
\begin{array}{rl}
\frac{\partial z}{\partial x_{u}}=m_{u}\left(x_{u}\right)-p_{o} & F\left(x_{u}\right)+\int_{\theta} \int_{y=0}^{x_{u}} \int_{x=x_{u}}^{\infty} \frac{\partial}{\partial x_{u}}\left[r_{s}\left(x, x-x_{u}, \theta\right) h\left(x, y\left(x_{u}\right), \theta\right)\right] d x d y d \theta \\
& +\int_{\theta} \int_{y=x_{u}}^{\infty} \int_{x=x_{u}}^{\infty} \frac{\partial}{\partial x_{u}}\left[r_{s}\left(x, x-y\left(x_{u}\right), \theta\right) h\left(x, y\left(x_{u}\right), \theta\right)\right] d x d y d \theta
\end{array}
$$

We get the condition for Proposition 1 by letting $\frac{\partial z}{\partial x_{u}}=0$.

\section{Proof of Proposition 3}

We will consider the two cases $y<x_{u}$ and $y \geq x_{u}$ separately and show that Proposition 3 holds for both cases. Consider $y \geq x_{u}$ first. Note that $y \geq x_{u}$ implies $\tilde{X}>x_{u}$ and that no penalty will be incurred under this scenario. Therefore,

$\Psi\left(x_{u}\right)=\operatorname{Pr}\{\pi \geq R\}=\operatorname{Pr}\left\{r_{u}\left(x_{u}\right)+r_{s}(\tilde{X}, \tilde{\omega}, \tilde{\theta}) \geq R\right\}$

Clearly, $\Psi\left(r_{u}^{-1}(R)\right)=1$, indicating $\Psi\left(x_{u}\right)$ is maximum at $x_{u}=r_{u}^{-1}(R)$. Next consider the case $y<x_{u}$. Using conditional probability under this condition,

$$
\begin{aligned}
& \Psi\left(x_{u}\right)=\operatorname{Pr}\{\pi \geq R\}=\operatorname{Pr}\left\{\pi \geq R \mid x \leq x_{u}\right\} \operatorname{Pr}\left\{x \leq x_{u}\right\}+\operatorname{Pr}\left\{\pi \geq R \mid x>x_{u}\right\} \operatorname{Pr}\left\{x>x_{u}\right\}, \\
& =\underbrace{\operatorname{Pr}\left\{r_{u}\left(x_{u}\right)-p_{o}\left(x_{u}-x\right) \geq R \mid x \leq x_{u}\right\}}_{A} F\left(x_{u}\right)+\underbrace{\operatorname{Pr}\left\{r_{u}\left(x_{u}\right)+r_{s}(x, \omega, \theta) \geq R \mid x>x_{u}\right.}_{B}\}\left\{1-F\left(x_{u}\right)\right\} .
\end{aligned}
$$

Note that at $x_{u}=r_{u}^{-1}(R)$, the term A above is zero, while the term B is one. Therefore,

$$
\Psi\left(r_{u}^{-1}(R)\right)=1-F\left(r_{u}^{-1}(R)\right) .
$$

When $x_{u} \geq r_{u}^{-1}(R)$, the term B in (A3) is equal to one. Therefore, from (A3):

$$
\Psi\left(x_{u}\right)=\operatorname{Pr}\left\{r_{u}\left(x_{u}\right)-p_{o}\left(x_{u}-x\right) \geq R \mid x \leq x_{u}\right\} F\left(x_{u}\right)+1-F\left(x_{u}\right)
$$




\section{Please share your stories about how Open Access to this item benefits you.}

$$
\begin{aligned}
& =\operatorname{Pr}\left\{r_{u}\left(x_{u}\right)-p_{o}\left(x_{u}-x\right) \geq R, x \leq x_{u}\right\}+1-F\left(x_{u}\right) \\
& =\operatorname{Pr}\left\{x \geq R / p_{o}+x_{u}-r_{u}\left(x_{u}\right) / p_{o}, x \leq x_{u}\right\}+1-F\left(x_{u}\right) \\
& =F\left(x_{u}\right)-F\left(R / p_{o}+x_{u}-r_{u}\left(x_{u}\right) / p_{o}\right)+1-F\left(x_{u}\right) \\
& =1-F\left(R / p_{o}+x_{u}-r_{u}\left(x_{u}\right) / p_{o}\right) \\
& \leq 1-F\left(r_{u}^{-1}(R)\right)=\Psi\left(r_{u}^{-1}(R)\right), \text { as } r_{u}^{-1}(R)<x_{u}-r_{u}\left(x_{u}\right) / p_{o}+R / p_{o}
\end{aligned}
$$

Note that when $x_{u}>r_{u}^{-1}(R)$, the assumption $p_{o}>m_{s}(0)$ and the concavity of $r_{u}($.$) together imply$ $r_{u}^{-1}(R)<x_{u}-r_{u}\left(x_{u}\right) / p_{o}+R / p_{o}$. Therefore, for $x_{u} \geq r_{u}^{-1}(R), \Psi\left(x_{u}\right)$ is maximum at $x_{u}=r_{u}^{-1}(R)$.

\section{Proof of Corollary 1}

It obvious from Proposition 3 that the maximum value of $\Psi\left(x_{u}\right)$ lies in the region $\left[0, r_{u}^{-1}(R)\right]$. By Lemma 1 the objective function of problem $\mathbf{P 1}$ is concave and is maximized at $\left.x_{u}^{*}\right|_{P 0}$. Therefore, when $\left.x_{u}^{*}\right|_{P 0} \leq r_{u}^{-1}(R)$, by Proposition $3,\left.x_{u}^{*}\right|_{P 1} \in\left[0, r_{u}^{-1}(R)\right]$. A similar argument can be made for the case $\left.x_{u}^{*}\right|_{P 0}>r_{u}^{-1}(R)$.

\section{Proof of Proposition 4}

Consider the two cases $y<x_{u}$ and $y \geq x_{u}$ separately. When $y \geq x_{u}$, from the proof of Proposition 3, $\Psi\left(r_{u}^{-1}(R)\right)=1 \geq \psi$. Therefore, $\mathbf{P 1}$ is always feasible. Next consider the case $y<x_{u}$. Using (A4), If $\Psi\left(r_{u}^{-1}(R)\right)=1-F\left(r_{u}^{-1}(R)\right) \geq \psi$ then problem $\mathbf{P 1}$ is feasible. Rearranging terms in this inequality, we get the stated sufficient condition for feasibility of P1. We next look at the upper bound of P1. When $y \geq x_{u}$, from (A1),

$$
\begin{aligned}
\Psi\left(x_{u}\right) & =\operatorname{Pr}\left\{r_{s}(\tilde{X}, \tilde{X}-\tilde{Y}, \tilde{\theta}) \geq R-r_{u}\left(x_{u}\right)\right\} \leq \operatorname{Pr}\left\{r_{s}\left(\tilde{X}, \tilde{X}-x_{u}, \tilde{\theta}\right) \geq R-r_{u}\left(x_{u}\right)\right\} \\
& =\operatorname{Pr}\left\{\tilde{X}>x_{u}, r_{s}\left(\tilde{X}, \tilde{X}-x_{u}, \tilde{\theta}\right) \geq R-r_{u}\left(x_{u}\right)\right\} \leq \operatorname{Pr}\left\{\tilde{X}>x_{u}\right\}=1-F\left(x_{u}\right)
\end{aligned}
$$

When $y<x_{u}$, the first term in the expression of $\Psi\left(x_{u}\right)$ in (A3) is zero. Thus,

$$
\Psi\left(x_{u}\right)=\operatorname{Pr}\left\{r_{u}\left(x_{u}\right)+\tilde{r}_{s}\left(x-x_{u}\right) \geq R \mid x>x_{u}\right\}\left\{1-F\left(x_{u}\right)\right\} \leq 1-F\left(x_{u}\right)
$$

Any feasible solution to $\mathbf{P 1}$ must satisfy:

$$
\Psi\left(x_{u}\right) \geq \psi \text {. }
$$

Combining (A6a), (A6b), and (A7) we get, $1-F\left(x_{u}\right) \geq \psi$ or $\left.x_{u}^{*}\right|_{P 1} \leq F^{-1}(1-\psi)$.

From Corollary $1,\left.x_{u}^{*}\right|_{P 1} \in\left[0, \max \left\{\left.x_{u}^{*}\right|_{P 0}, r_{u}^{-1}(R)\right\}\right]$. Combining these two results, we get the desired result.

\section{Proof of Lemma 2}

Using the notation from the proof of Lemma $1, \Psi\left(x_{u}\right)=\operatorname{Pr}\{\pi \geq R\}=\operatorname{Pr}\left\{r_{u}\left(x_{u}\right)+q\left(x_{u} ; x, y, \theta\right) \geq R\right\}$. We have established in the proof of Lemma 1 that $q\left(x_{u} ; x, y, \theta\right)$ is concave in $x_{u}$. By assumption, $r_{u}\left(x_{u}\right)$ is also concave in $x_{u}$. Therefore, $\pi\left(x_{u}\right)=r_{u}\left(x_{u}\right)+q\left(x_{u} ; x, y, \theta\right)$ is concave in $x_{u}$, implying that if $\pi\left(x_{u}\right)$ is decreasing at $x_{u}=\bar{x}_{u}$ then it cannot be increasing at any $x_{u} \geq \bar{x}_{u}$. To see that the same result holds for $\Psi\left(x_{u}\right)=\operatorname{Pr}\{\pi \geq R\}$, consider two values of $x_{u}, \bar{x}_{u}$ and $\bar{x}_{u}+\varepsilon$, with $\varepsilon>0$ and 
Please share your stories about how Open Access to this item benefits you.

assume that $\Psi\left(x_{u}\right)$ is decreasing at $x_{u}=\bar{x}_{u}$. Given $\Psi\left(x_{u}\right)$ is decreasing, it follows that $\pi\left(x_{u}\right)$ is decreasing as well at $x_{u}=\bar{x}_{u}$. Therefore,

$$
\begin{aligned}
\Psi\left(\bar{x}_{u}\right) & =\operatorname{Pr}\left\{r_{u}\left(\bar{x}_{u}\right)+q\left(\bar{x}_{u} ; x, y, \theta\right) \geq R\right\} \\
& =\operatorname{Pr}\left\{r_{u}\left(\bar{x}_{u}+\varepsilon\right)+q\left(\bar{x}_{u}+\varepsilon ; x, y, \theta\right)+K \geq R\right\}, \text { where } \mathrm{K} \text { is a constant, as } \pi\left(\bar{x}_{u}+\varepsilon\right) \leq \pi\left(\bar{x}_{u}\right) \\
& \geq \operatorname{Pr}\left\{r_{u}\left(\bar{x}_{u}+\varepsilon\right)+q\left(\bar{x}_{u}+\varepsilon ; x, y, \theta\right) \geq R\right\}=\Psi\left(\bar{x}_{u}+\varepsilon\right), \text { as adding a constant leads to first }
\end{aligned}
$$

order stochastic dominance.

\section{Proof of Theorem 1}

It is obvious that $\left.x_{u}^{*}\right|_{P 1}=\left.x_{u}^{*}\right|_{P 0}$ when $\Psi\left(\left.x_{u}^{*}\right|_{P 0}\right) \geq \psi$

(a). Assume $\Psi\left(\left.x_{u}^{*}\right|_{P 0}\right)<\psi$ and that $\Psi\left(x_{u}\right)$ is increasing in $x_{u}$ in the region $\left[0, r_{u}^{-1}(R)\right]$. By

Proposition 3, in the region $x_{u}>r_{u}^{-1}(R), \Psi\left(x_{u}\right)$ is maximum at $x_{u}=r_{u}^{-1}(R)$. Therefore, for feasibility of $\mathbf{P 1}$ we must have $\Psi\left(r_{u}^{-1}(R)\right) \geq \psi$. Given the concavity of the objective function, it is easy to see that $\left.x_{u}^{*}\right|_{P 1}$ solves $\Psi_{1}\left(x_{u}\right)=\psi$ when $\left.x_{u}^{*}\right|_{P 0} \leq r_{u}^{-1}(R)$ while it solves $\Psi_{2}\left(x_{u}\right)=\psi$ when $\left.x_{u}^{*}\right|_{P 0}>r_{u}^{-1}(R)$.

(b). The proof for part (b) is similar to that of part (a), and hence is omitted.

(c). Follows directly from Lemma 2

\section{Proof of Corollary 2}

When $\left.x_{u}^{*}\right|_{P 0} \leq r_{u}^{-1}(R)$, if there exists an $x_{u}<\left.x_{u}^{*}\right|_{P 0}$ for which $\Psi\left(x_{u}\right) \geq \psi$, then $\Psi\left(\left.x_{u}^{*}\right|_{P 0}\right) \geq \psi$ as well and that $\left.x_{u}^{*}\right|_{P 1}=\left.x_{u}^{*}\right|_{P 0}$. If $\Psi\left(\left.x_{u}^{*}\right|_{P 0}\right)<\psi$, then $\left.x_{u}^{*}\right|_{P 1}>\left.x_{u}^{*}\right|_{P 0}$.

\section{Proof of Proposition 5}

It follows from Corollary 1 that the maximum value of $\Psi\left(x_{u}\right)$ lies in the region $\left[0, r_{u}^{-1}(R)\right]$. Observe from the expression of $\Psi\left(x_{u}\right)$ in (8) that it is independent of the penalty cost $p_{o}$ in this region. Look at the optimal solution of problem $\mathbf{P 1}$ next. If possible, let $\left.x_{u}^{*}\right|_{P 1}$ be dependent on $p_{o}$. When $\left.x_{u}^{*}\right|_{P 0} \leq r_{u}^{-1}(R)$, by Theorem 1 , any optimal solution of P1 must satisfy $\left.x_{u}^{*}\right|_{P 1} \leq r_{u}^{-1}(R)$, implying the condition $r_{u}\left(x_{u}\right) \leq R$ must be satisfied. When $x \leq x_{u}$, a penalty is incurred. Under such a situation the total revenue of the network must be less than $r_{u}\left(x_{u}\right)$, which in turn is less that $R$. Therefore, the constraint $\Psi\left(x_{u}\right) \geq \psi$ can no longer be satisfied under this scenario. Therefore, $\left.x_{u}^{*}\right|_{P 1}$ must be independent of the penalty cost $p_{o}$.

\section{Proof of Proposition 6}

It is easy to see from (A2) that $\Psi\left(x_{u}\right)$ is increasing in a stronger Upfront. Note that for any arbitrary distribution of $\tilde{X}$, the first term in (A3)is increasing in a stronger Upfront. Similarly, for any arbitrary distributions of $\tilde{r}_{s}($.) and $\tilde{X}$, the second term in (A3) is also increasing in a stronger Upfront. Therefore, 


\section{Please share your stories about how Open Access to this item benefits you.}

$\Psi\left(x_{u}\right)$ is increasing in a stronger Upfront. This allows smaller values of $x_{u}^{*}$, closer to $\left.x_{u}^{*}\right|_{P 0}$, to become an optimal solution of P1 when $\left.x_{u}^{*}\right|_{P 1} \geq\left. x_{u}^{*}\right|_{P 0}$. As a result, $\left.x_{u}^{*}\right|_{P 1}$ is non-increasing in a stronger Upfront. A similar argument can be made for the $\left.x_{u}^{*}\right|_{P 1}<\left.x_{u}^{*}\right|_{P 0}$.

\section{Proof of Proposition 7}

Increasing the mean of a random variable while keeping its variance constant is simply equivalent to adding a constant positive term to it. This gives rise to first order stochastic dominance. Thus, for any random variable $X$ and any constant $a, \operatorname{Pr}\{X \geq a\}=1-F(a)$ increases as the mean of $X$ increases while its variance is held constant. This implies that $\Psi_{2}\left(x_{u}\right)$ increases as the mean of $\tilde{X}$ increases while its variance is held constant. Given $r_{s}($.$) is an increasing$ function of $x, \Psi_{1}\left(x_{u}\right)$ also increases as the mean of $\tilde{X}$ increases while its variance is held constant. Consider the case $\left.x_{u}^{*}\right|_{P 0} \leq r_{u}^{-1}(R)$ and $\Psi_{1}\left(x_{u}\right)$ is increasing in $x_{u}$. Under this scenario, by Theorem 1, the optimal solution of $\mathbf{P 1}$ is given by the $\Psi_{1}\left(x_{u}\right)=\psi$ and that the relationship $\left.x_{u}^{*}\right|_{P 1} \geq\left. x_{u}^{*}\right|_{P 0}$ holds. In this case, as the mean of $\tilde{X}$ increases, $\Psi_{1}($.$) also increases. Therefore, the$ solution of $\Psi_{1}\left(x_{u}\right)=\psi$ decreases implying $\left.x_{u}^{*}\right|_{P 1}$ is also non-increasing in the mean of $\tilde{X}$ when its variance is held constant. A similar analysis can be done for the three additional cases involving whether $\Psi_{1}\left(x_{u}\right)$ is increasing in $x_{u}$ and whether the relationship $\left.x_{u}^{*}\right|_{P 0} \leq r_{u}^{-1}(R)$ holds. In each of these three cases, $\left.x_{u}^{*}\right|_{P 1}<\left.x_{u}^{*}\right|_{P 0}$ and that $\left.x_{u}^{*}\right|_{P 1}$ is also non-decreasing in the mean of $\tilde{X}$ when its variance is held constant. This proves our result. 
Bollapragada, Srinivas, and Suman Mallik. "Managing On-air Ad Inventory in Broadcast Television." IIE Transactions 40.12

(2008): 1107-123. Publisher's official version: http://dx.doi.org/10.1080/07408170802323026. Open Access version:

http://kuscholarworks.ku.edu/dspace/.

Please share your stories about how Open Access to this item benefits you.

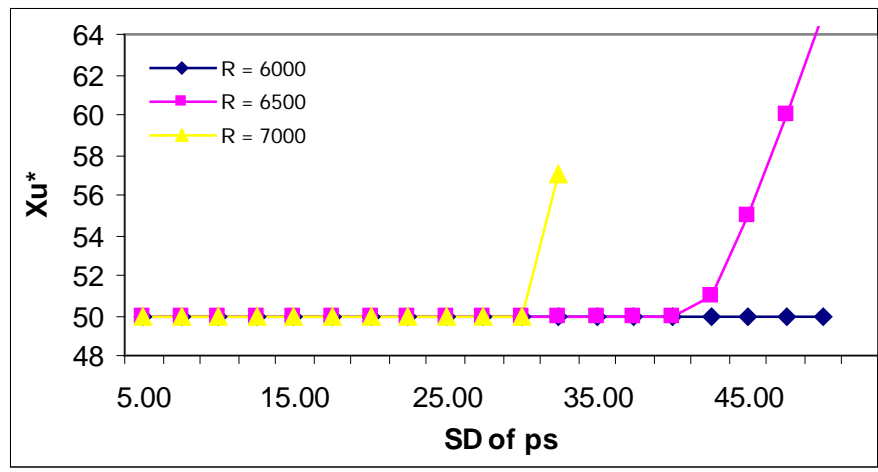

Figure 1(a): Sensitivity of $\left.x_{u}^{*}\right|_{P 1}$ wrt $\sigma_{p s}$

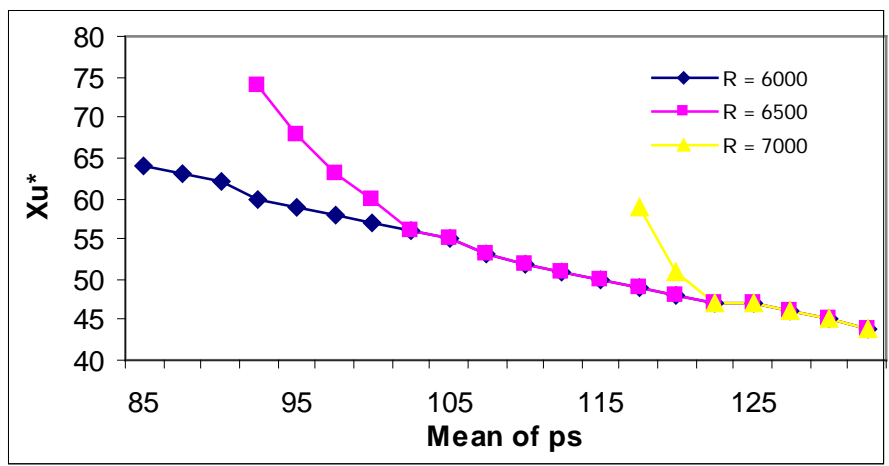

Figure 2(a): Sensitivity of $\left.x_{u}^{*}\right|_{P 1}$ wrt $\mu_{p s}$

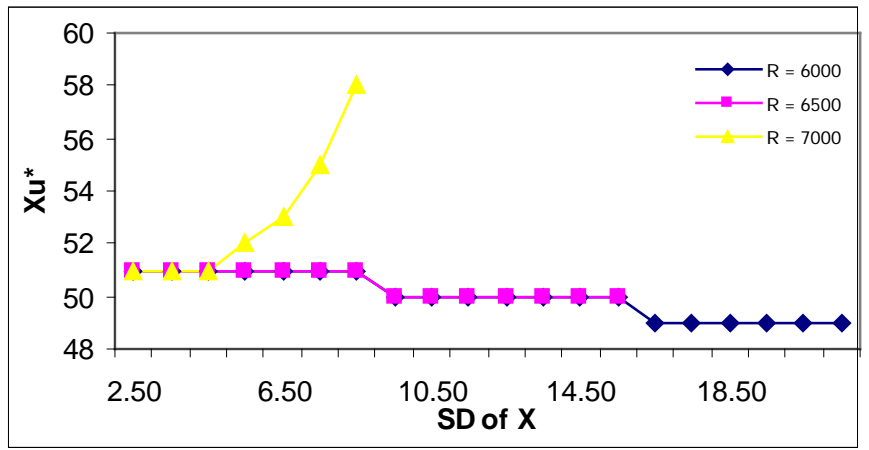

Figure 3(a): Sensitivity of $\left.x_{u}^{*}\right|_{P 1}$ wrt $\sigma_{X}$

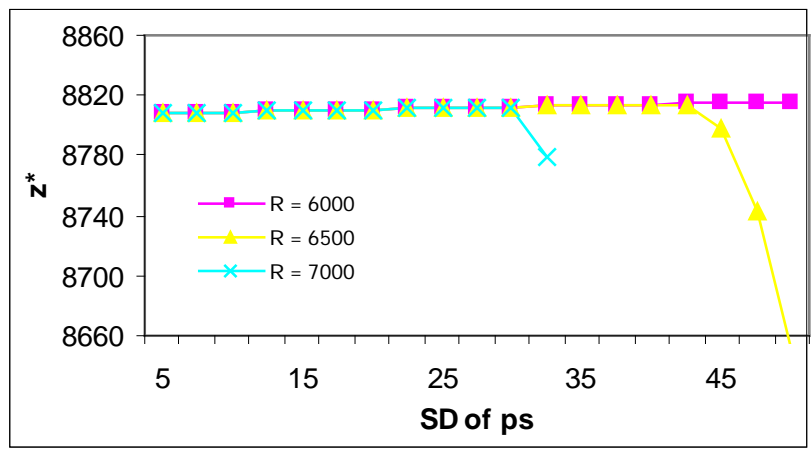

Figure 1(b): Sensitivity of $z^{*}$ wrt $\sigma_{p s}$

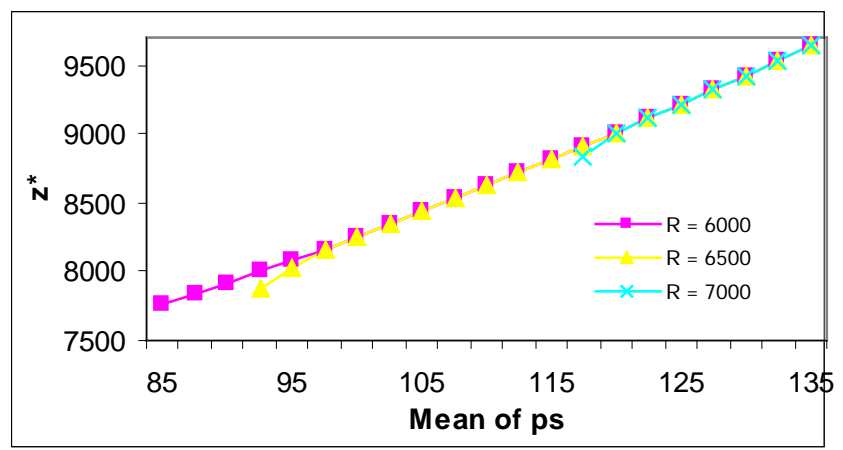

Figure 2(b): Sensitivity of $z^{*}$ wrt $\mu_{p s}$

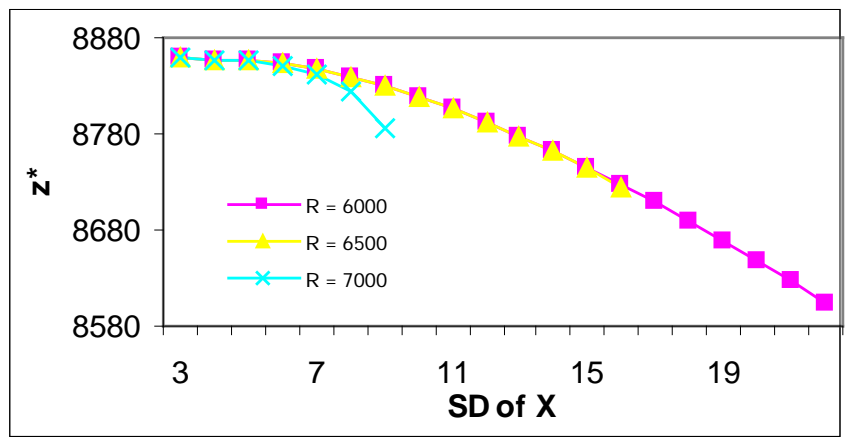

Figure 3(b): Sensitivity of $z^{*}$ wrt $\sigma_{X}$ 
Bollapragada, Srinivas, and Suman Mallik. "Managing On-air Ad Inventory in Broadcast Television." IIE Transactions 40.12

(2008): 1107-123. Publisher's official version: http://dx.doi.org/10.1080/07408170802323026. Open Access version:

http://kuscholarworks.ku.edu/dspace/.

Please share your stories about how Open Access to this item benefits you.

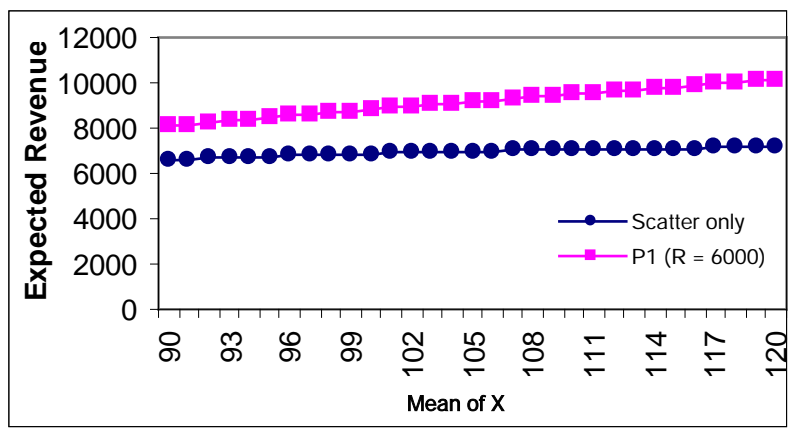

Figure 4(a): Expected revenue as a function of $\mu_{X}$

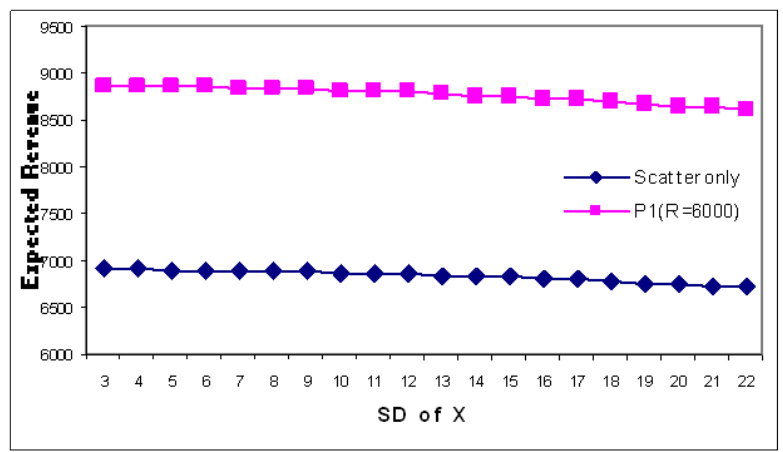

Figure 4(b): Expected revenue as a function of $\sigma_{X}$

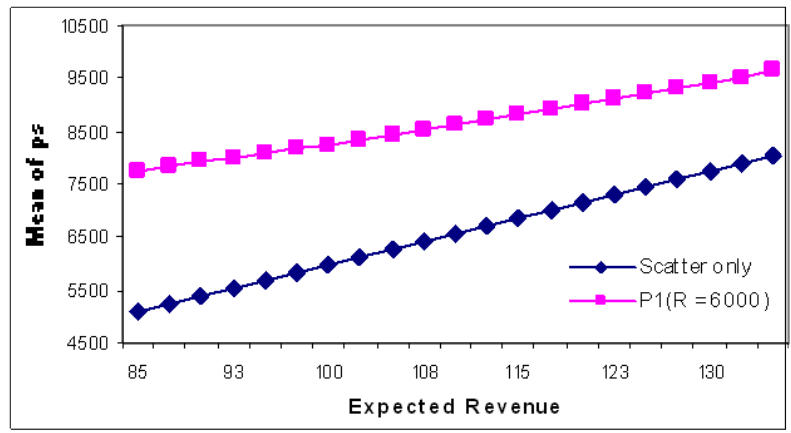

Figure 4(c): Expected revenue as a function of $\mu_{p s}$

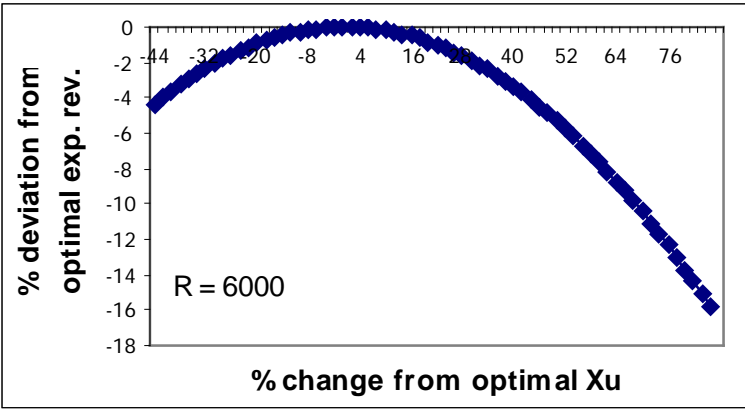

Figure 5: \% deviation from optimal expected revenue with respect to change in $x_{u}$ 